University of Louisville

ThinkIR: The University of Louisville's Institutional Repository

Electronic Theses and Dissertations

$12-2016$

\title{
TNF-like weak inducer of apoptosis (TWEAK) : not so weak after all.
}

Joseph Dekward McMillan IV

University of Louisville

Follow this and additional works at: https://ir.library.louisville.edu/etd

Part of the Molecular Biology Commons

\section{Recommended Citation}

McMillan, Joseph Dekward IV, "TNF-like weak inducer of apoptosis (TWEAK) : not so weak after all." (2016). Electronic Theses and Dissertations. Paper 2617.

https://doi.org/10.18297/etd/2617

This Master's Thesis is brought to you for free and open access by ThinkIR: The University of Louisville's Institutional Repository. It has been accepted for inclusion in Electronic Theses and Dissertations by an authorized administrator of ThinkIR: The University of Louisville's Institutional Repository. This title appears here courtesy of the author, who has retained all other copyrights. For more information, please contact thinkir@louisville.edu. 
TNF-LIKE WEAK INDUCER OF APOPTOSIS (TWEAK): NOT SO WEAK AFTER ALL

\author{
By \\ Joseph Delward McMillan IV \\ B.S., University of Louisville, 2014
}

\begin{abstract}
A Thesis
Submitted to the Faculty of the

School of Medicine of the University of Louisville

in Partial Fulfillment of the Requirements

for the Degree of
\end{abstract}

Master of Science

in Anatomical Sciences and Neurobiology

Department of Anatomical Sciences and Neurobiology

University of Louisville

Louisville, Kentucky

December 2016 

TNF-LIKE WEAK INDUCER OF APOPTOSIS (TWEAK): NOT SO WEAK AFTER ALL

\author{
By \\ Joseph Delward McMillan IV \\ B.S., University of Louisville, 2014
}

A thesis approved on

September $9^{\text {th }}, 2016$

by the following Thesis Committee:

Dr. Ashok Kumar

Dr. Robert Friedland

Dr. Patrick Moore 


\section{ACKNOWLEDGEMENTS}

I would like to thank my mentor, Dr. Ashok Kumar, for his patience, guidance, and for pushing me to improve every day. He truly cares about his students and does whatever he can to help them achieve their goals. I would also like to thank my other committee members, Dr. Robert Friedland and Dr. Pat Moore, for their flexibility and assistance in completing this thesis. Yuji Ogura also deserves credit for helping me get this project off the ground, and without his help, I would not have been nearly as successful in this pursuit. Also, I would like to thank my lab mates: Kyle Bohnert, Yann Gallot, Sajedah Hindi, Guang Xiong, Alex Straughn, and Anna Bankston. These are the kind individuals that have taught me everything that I know in the lab and have been in the trenches with me through the ups and downs of research. Finally, I would like to thank my family for their abiding support. 


\begin{abstract}
TNF-LIKE WEAK INDUCER OF APOPTOSIS (TWEAK): NOT SO WEAK AFTER ALL Joseph D. McMillan IV

September $9^{\text {th }}, 2016$

Background: Tumor necrosis factor (TNF)-like weak inducer of apoptosis (TWEAK) is a proinflammatory cytokine belonging to the TNF super family. TWEAK produces a variety of cellular responses through the binding to fibroblast growth factor inducible 14 (Fn14), a member of TNF receptor superfamily. Although Fn14 lacks a death domain, TWEAK has been found to induce apoptosis in some cell types by perturbing the activity of certain pathways such as TNF-receptor signaling. TWEAK is also known to regulate proliferation and differentiation of myogenic cells. We have previously reported that the TWEAKFn14 system causes skeletal muscle wasting both in vitro and in vivo. In addition, it has been reported that TWEAK is a mediator of atrophy in disuse conditions such as denervation. However, it remains unknown whether TWEAK can affect the viability of muscle cells.
\end{abstract}

Hypothesis: TWEAK induces oxidative stress and cell death in myotube cultures. 
Methods: We used primary myogenic cells and biochemical assays to study the effects of recombinant TWEAK protein on the survival of cultured mouse primary myotubes.

Results: Our results demonstrate that TWEAK reduces myotube viability in a dose-dependent manner evident by increased levels of lactate dehydrogenase (LDH) in culture supernatants. Furthermore, we have found that the levels of cleaved poly (ADP-ribose) polymerase (PARP) and cleaved (activated) caspase3 are increased upon treatment with TWEAK. TWEAK also induces oxidative stress in cultured myotubes. A general antioxidant, N-acetyl-L-cysteine (NAC), partially blocked TWEAK-induced cytotoxicity in cultured myotubes.

Conclusions: Our results provide initial evidence that in addition to causing atrophy, TWEAK can also diminish skeletal muscle mass by inducing oxidative stress, which diminishes the survival of myofibers in catabolic conditions. 


\section{TABLE OF CONTENTS}

\section{PAGE}

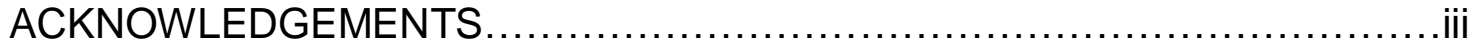

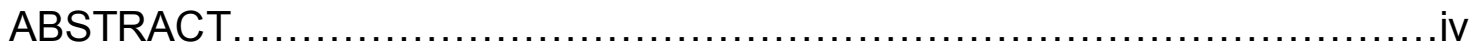

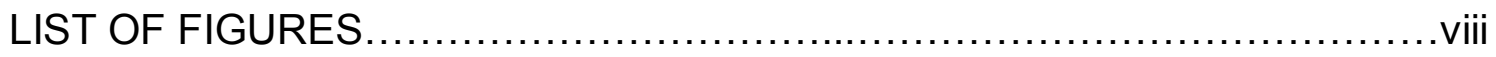

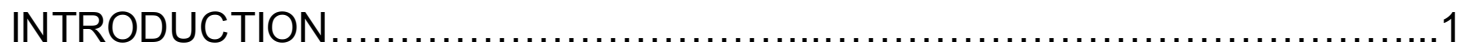

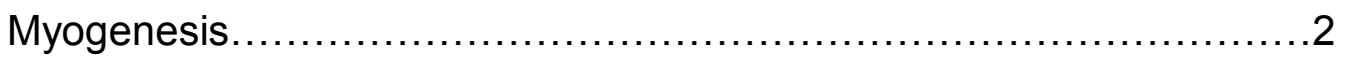

Signaling mechanisms regulating skeletal muscle mass................... 3

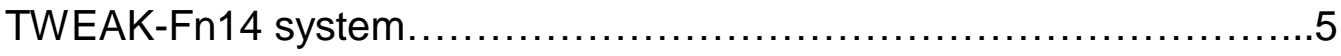

TWEAK-Fn14 system in myogenesis................................. 6

TWEAK and skeletal muscle metabolism..............................

TWEAK-Fn14 system and skeletal muscle atrophy .....................11

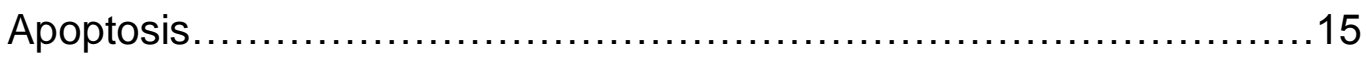

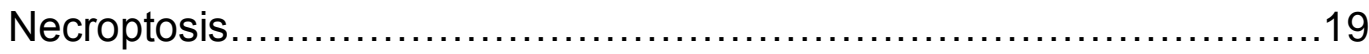

Regulation of Redox homeostasis ......................................20

Oxidative Stress in Skeletal Muscle......................................23

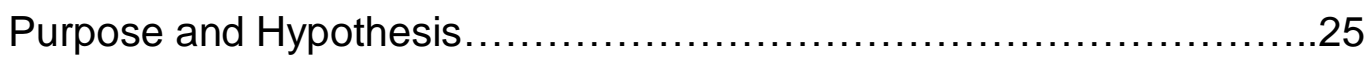

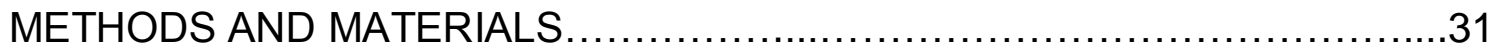

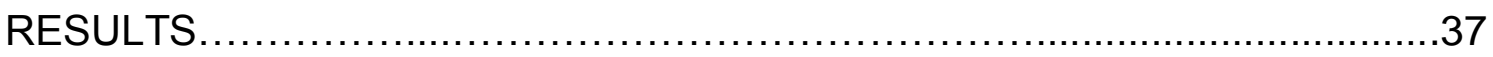

TWEAK induces cytotoxicity in mouse primary myotube cultures..........37

TWEAK induces apoptosis in myotube cultures..........................38 
TWEAK increases the levels of various biochemical markers of apoptosis

in cultured myotubes.

Z-VAD-FMK, a pan-caspase inhibitor reduces the TWEAK-induced

cytotoxicity in myotube cultures......................................40

TWEAK induces necroptosis in cultured myotubes......................40

TWEAK induces oxidative stress in cultured myotubes...................41

TWEAK perturbs the expression of various pro-oxidant and antioxidant molecules in cultured myotubes....................................... 42

$\mathrm{N}$-acetyl Cysteine (NAC) reduces cell death in TWEAK-treated primary

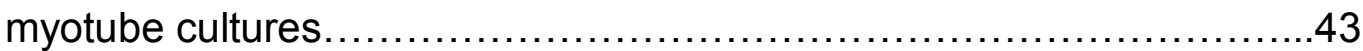

TWEAK perturbs oxidative stress in skeletal muscle during

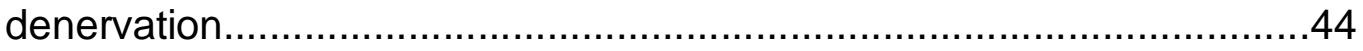

CONCLUSIONS AND FUTURE WORK ......................................56

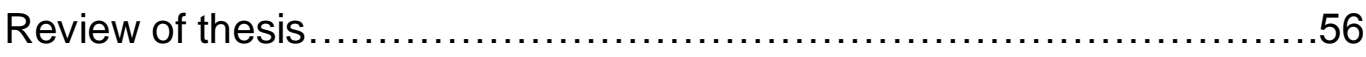

Contribution of thesis and future implementations.......................59

Limitations of future implementations .................................61

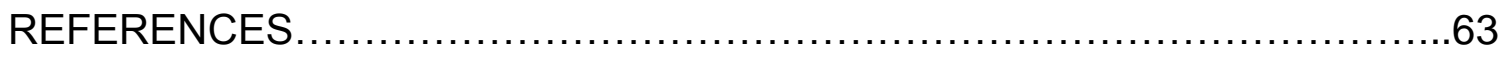

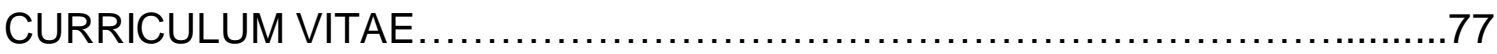




\section{LIST OF FIGURES}

FIGURES

PAGE

1.1 TWEAK's effect on myogenesis

1.2 Schematic illustration of TWEAK and downstream signaling cascades.

1.3 Physiological Effects of TWEAK ..................................30

3.1 TWEAK induces cytotoxicity in mouse primary myotube cultures...45

3.2 TWEAK induces apoptosis in myotube cultures. 46

3.3 TWEAK increases the levels of biochemical markers of apoptosis in cultured myotubes.

3.4 Inhibition of caspases reduces TWEAK-induced cytotoxicity in myotube cultures.

3.5 TWEAK induces necroptosis in cultured myotubes.

3.6 TWEAK induces oxidative stress in cultured myotubes.

3.7 TWEAK perturbs the expression of various oxidant and antioxidant molecules in cultured myotubes.

3.8 N-acetyl cysteine (NAC) inhibits TWEAK-induced cell death in myotube cultures. .53

3.9 Absence of TWEAK perturbs the antioxidant and oxidant mRNA expression after denervation 


\section{CHAPTER 1: INTRODUCTION}

Skeletal muscle is the most abundant tissue of the human body, which provides structural support, enables the body to maintain posture, and ensures basic functions such as locomotion, respiration, energy storage, and whole body metabolism. Skeletal muscle is also a highly plastic tissue. Skeletal muscle undergoes hypertrophy in response to various physiological stressors, such as weight bearing and exercise. Skeletal muscle remodels by activating multiple signaling pathways to reprogram gene expression to sustain muscle mass, energy metabolism, and performance. By contrast, loss of skeletal muscle mass (i.e. muscle atrophy/wasting) is a devastating consequence of a large number of chronic disease states and several other conditions such as: starvation, denervation, immobilization, and aging ${ }^{1,2}$. However, there is currently no drug approved for the prevention or treatment of muscle wasting, partly because the mechanisms of muscle growth/hypertrophy and atrophy remain poorly understood ${ }^{3}$. Over the past several years, our laboratory has identified the cytokine, TWEAK, as a potent mediator of muscle wasting in many conditions. The mechanisms by which TWEAK induces skeletal muscle wasting remain less understood. The major goal of my thesis was to investigate the mechanisms of action of TWEAK in skeletal muscle with a focus on oxidative stress and survival of muscle cells. In the following sections, I provide a succinct description of the processes involved in the regulation of skeletal muscle mass. 


\section{Myogenesis}

Myogenesis is a highly coordinated process by which skeletal muscle is formed during embryonic development (Figure 1.1). The process of myogenesis is also required for regeneration of injured myofibers and skeletal muscle growth in response to anabolic cues ${ }^{4,5}$. During embryonic development, skeletal muscle originates from the paraxial mesoderm, forming somites, then the dermomyotome, and finally the myotome. Myoblasts undergo frequent cell divisions and eventually fuse together leading to the formation of multinucleated myotubes/myofibers ${ }^{6}$. In postnatal skeletal muscle, a fraction of the muscle progenitor cells, known as satellite cells, enter quiescence and reside underneath the basal lamina of adult muscle fibers ${ }^{5,7}$. Skeletal muscle is a terminally differentiated tissue, yet it possesses a remarkable capability to regenerate in response to injury, an ability attributable to satellite cells. Upon injury, satellite cells reenter the cell cycle, proliferate, and subsequently differentiate into myoblasts. Myoblasts differentiate into myocytes, which fuse with injured myofibers to complete the process of myofiber regeneration ${ }^{5,8}$. While a vast majority of activated satellite cells progress into the myogenic lineage and contribute to muscle repair, a very small proportion of them undergo self-renewal and return to quiescence to replenish the pool of satellite cells for future rounds of skeletal muscle repair.

Skeletal muscle formation is regulated by the sequential expression of a number of myogenic transcription factors. Paired-box (Pax) 3 and Pax7 transcription factors are involved in early lineage specification ${ }^{4}$. Pax7 is almost 
exclusively expressed in satellite cells, which are critical for the self-renewal and maintenance of their myogenic potential in adult skeletal muscle ${ }^{8}$. Following specification to the myogenic lineage, the levels of $\operatorname{Pax} 7$ are reduced, whereas the levels of Myf5 and MyoD transcription factors are increased, which results in the formation of proliferating myoblasts. After several rounds of cell division, myoblasts differentiate into myocytes, which express the late myogenic regulatory factors (MRFs), myogenin (MyoG) and MRF4. Myocytes then fuse with one another to form multinucleated myotubes/myofibers, which express both the late MRFs and the specific muscle proteins that are required for maintenance of contractile function and metabolic activity ${ }^{8,9}$. Additional heterogeneity develops in the form of skeletal muscle fiber types that vary in their metabolic capacity and protein expression in accordance with the context-dependent function of the specific muscle.

\section{Signaling mechanisms regulating skeletal muscle mass}

In the context of acute, everyday stressors, such as weight bearing and exercise, skeletal muscle responds by activating multiple signaling pathways that promote the expression of genes that alter muscle mass, energy metabolism, and performance to meet environmental demands. In similar fashion, as the environmental demands change due to prolonged inactivity or chronic disease states, the skeletal muscle responds by initiating signaling cascades that lead to

muscle atrophy or wasting in a context-dependent manner ${ }^{10}$. Skeletal muscle mass is maintained through a delicate balance between the rate of protein 
synthesis and degradation ${ }^{2,11}$. Resistance exercise, hormones, and nutritional uptake increase the rate of protein synthesis resulting in muscle hypertrophy 1,12,13. IGF1/PI3K/Akt/mTOR is an important signaling pathway which increases protein synthesis leading to skeletal muscle hypertrophy ${ }^{14,15}$. Activation of this pathway also inhibits muscle protein degradation through distinct mechanisms 16,17. While activation of canonical TGF- $\beta$ family members (e.g. myostatin and activin), which function through activin receptors and activation of transcription factors Smad2/3, causes muscle wasting ${ }^{18}$, recent studies have provided strong evidence that the activation of the bone morphogenetic protein (BMP)-Smad1/5/8 signaling pathway induces muscle growth ${ }^{19-21}$. Activation of the BMP-Smad1/5/8 pathway also counters skeletal muscle wasting in many catabolic states ${ }^{22,23}$. Interestingly, preliminary studies in our lab suggest that transforming growth factor beta-activated kinase 1 (TAK1) is an important regulator of both PI3K/Akt/mTOR and (BMP)-Smad1/5/8 signaling and that these two pathways may cross-talk through TAK1 to promote muscle growth.

The ubiquitin-proteasome system (UPS) is a major proteolytic mechanism in skeletal muscle. Proteases such as caspases and calpains may also be required for initial cleavage of the myofibrillar components, thereby accelerating disassembly and degradation by the UPS ${ }^{24,25}$. The activity of UPS is increased in response to many extracellular stimuli such as inflammatory cytokines, tumorderived factors, and oxidative stress. Additionally, the UPS is also activated in many disuse conditions such as denervation, immobilization, and unloading. A number of E3 ubiquitin ligases such as: MuRF1, MAFBx (Atrogin-1), Nedd4.1, 
and MUSA1 have now been identified which cause proteolytic degradation of thick and thin filament proteins in skeletal muscle ${ }^{20,26,27}$. While excessive activation of the autophagy-lysosomal pathway can lead to muscle wasting ${ }^{1,13,17}$, accumulating evidence suggests that some level of autophagy is essential to maintaining skeletal muscle health and function. Inhibition of basal autophagy leads to myopathy and excessive loss of muscle mass due to accumulation of dysfunctional organelles, dysfunctional proteins, and oxidative stress ${ }^{28-30}$. The activity of UPS and/or autophagy is regulated through the activation of a number of signaling pathways such as PI3K/Akt/mTOR, p38MAPK, AMP-activated protein kinase (AMPK), and nuclear factor-kappa $\mathrm{B}(\mathrm{NF}-\mathrm{kB})$ which function through modulating the activity of various transcriptional regulators ${ }^{1,13,31-36}$. Furthermore, it is also now evident that changes in the mitochondrial content, integrity, and function also play critical roles in the regulation of muscle mass $1,37,38$.

\section{TWEAK-Fn14 system}

TNF-like weak inducer of apoptosis (TWEAK) is a member of the TNF superfamily (TNFSF). The TNFSF is a 19-member group of type II transmembrane proteins that are involved in the regulation of a plethora of normal cellular responses including: immune response, hematopoiesis, and morphogenesis ${ }^{39,40}$. However, the TNFSF has also been implicated in many disease states such as: tumorigenesis, transplant rejection, septic shock, viral replication, bone resorption, and cachexia ${ }^{39,41}$ among others. TWEAK is 
expressed as a 249 amino acid (aa) type II transmembrane protein and similar to other members of the TNFSF can be proteolytically cleaved into a soluble, biologically active 156 aa cytokine ${ }^{42}$. Structurally, soluble TWEAK can be characterized as an anti-parallel $\beta$-sheet that binds to the fibroblast growth factor inducible-14 receptor (Fn14) as a homotrimer ${ }^{42,43}$. Between the trimers, there are grooves that serve as the binding sites for the Fn14 receptor ${ }^{43}$.

The characterization of a TNF-receptor super family (TNFRSF) member with TWEAK-binding activity was initially reported by Wiley et al. in $2001^{43,44}$. Originally it was given the name TweakR, but the predicted protein sequence was found to be identical to the Fn14 receptor discovered in 1999 by MeighanMantha et $\mathrm{al}^{45}$. TWEAK binds exclusively to the Fn14 receptor and the Fn14 receptor does not bind any other member of the TNFSF ${ }^{43}$. The Fn14 receptor is a 129 aa type I transmembrane protein and is the smallest member of the TNFRSF $^{43,44}$. In the 53 aa extracellular ligand-binding domain, the Fn14 receptor contains a single cysteine-rich subdomain in contrast to other members of the TNFRSF that contain three or four ${ }^{43}$. The intracellular signaling capacity of Fn14 relies on the 29 aa cytoplasmic domain, which contains a single TNFRassociated factor (TRAF) binding site $\mathrm{e}^{40,46,47}$. The Fn14 receptor is able to associate with four of the six TRAF proteins, TRAF1, TRAF2, TRAF3, and TRAF5, at the predicted sequence motif ${ }^{44,48}$. These adaptor proteins lead to a vast array of signaling capabilities mediated by the TWEAK-Fn14 signaling axis.

\section{TWEAK-Fn14 system in myogenesis}


While TWEAK is constitutively and ubiquitously expressed in a number of different cell types as a Type II transmembrane protein, the Fn14 receptor is expressed at very low levels in healthy, mature tissue ${ }^{49}$. However, in response to injury and disease conditions, the expression of the Fn14 receptor is dramatically increased and TWEAK undergoes furin-mediated cleavage to its secreted form. It is also notable that in contrast to mature muscle fibers, satellite cells and primary myoblasts constitutively express the Fn14 receptor ${ }^{50,51}$. Overall, the Fn14 receptor serves as the rate-limiting step in the TWEAK-Fn14 signaling axis ${ }^{49}$.

The TWEAK-Fn14 dyad has important roles in the regulation of skeletal muscle mass. Previous studies from our laboratory have shown that TWEAK induces myoblast proliferation but inhibits their differentiation into multinucleated myotubes by reducing the stability of the MyoD protein and inhibiting the expression of myogenin (Figure 1.1) ${ }^{51,52}$. This inhibitory effect of TWEAK on myogenesis is mediated through the canonical arm of the NF-KB signaling pathway as evidenced by improved myogenesis in cells overexpressing a dominant negative mutant of $\mathrm{I}_{\mathrm{K}} \mathrm{B}$ kinase $(\mathrm{IKK}) \beta$, but not IKK $\mathrm{K}^{52}$. Intriguingly, recent studies have shown that TWEAK can also induce myoblast fusion. While high levels of TWEAK ( $\geq 100 \mathrm{ng} / \mathrm{ml}$ ) inhibit the differentiation of myoblasts into myotubes, low levels of TWEAK ( $10 \mathrm{ng} / \mathrm{ml})$ have been shown to facilitate fusion of myoblasts leading to the formation of larger myotubes ${ }^{12}$. The pro-fusion role of TWEAK at lower concentrations was shown to be mediated through activation of the non-canonical NF-KB signaling cascade ${ }^{53}$. 
The commitment of satellite cells to undergo self-renewal or differentiate into myogenic cells is characterized by expression of the proteins, Pax7 and MyoD. Satellite cells are $\mathrm{Pax} 7^{+} / \mathrm{MyoD}^{-}$, whereas differentiated myoblasts are Pax7-MyoD ${ }^{+}$. Ex vivo studies on myofiber explants have shown that low levels of TWEAK $(10 \mathrm{ng} / \mathrm{ml})$ decrease the number of Pax $7^{+} / \mathrm{MyoD}^{-}$satellite cells and increase the proportion of $\mathrm{Pax} 7^{-} / \mathrm{MyoD}^{+}$myoblasts through repression of Notch signaling and activation of NF-KB signaling ${ }^{54}$. With TWEAK inducing canonical NF-KB signaling in one aspect of myogenesis and non-canonical NF-KB signaling in another, it would seem that there is cross-talk between the two to facilitate successful myogenesis.

The regenerative capacity of mature muscle is crucial for good health and impairment in the regenerative process is a mainspring in the loss of skeletal muscle in many diseases ${ }^{55,56}$. Intramuscular injection of cardiotoxin (CTX) is a proven model for inducing satellite cell-driven muscle regeneration. The expression of TWEAK and Fn14 are greatly increased 3-5 days post-CTX injection in WT mice. TWEAK appears to negatively regulate skeletal muscle regeneration in vivo. Skeletal muscle regeneration was significantly improved in TWEAK-knockout (KO) mice compared to wild-type mice ${ }^{57}$. The exact opposite phenotype was observed in TWEAK-transgenic $(\mathrm{Tg})$ mice which overexpress TWEAK in skeletal muscle ${ }^{57}$. In accordance with the data from myofiber explants, the number of satellite cells was also significantly increased in the regenerating myofibers of TWEAK-KO mice ${ }^{54}$. Additionally, TWEAK is known to be a pro-inflammatory molecule, which in the context of higher concentrations or 
chronic disease states may perturb the normal immune response, leading to a cytotoxic environment that is not conducive to regeneration ${ }^{56,58}$. Collectively, these findings suggest that elevated levels of TWEAK impair skeletal muscle regeneration.

\section{TWEAK and skeletal muscle metabolism}

Skeletal muscle contains four different fiber types: I, IIA, IIX, IIB each expressing a different myosin heavy chain $(\mathrm{MyHC})$ isoform and having specific metabolic qualities $^{10,59-61}$. Skeletal muscle maintains the ability to transition from one fiber type to another depending on the specific needs of the muscle as a whole ${ }^{10,59,62}$ with MyHC type I fibers being considered "slow oxidative" and MyHC type II fibers being considered "fast glycolytic." The type I fibers are considered to have a high mitochondrial content, prefer fatty acid oxidation, and exhibit a slower contraction-relaxation profile. In contrast, type IIB fibers have less mitochondrial content, prefer glycolytic metabolism, and exhibit a much faster contractionrelaxation profile. Along this spectrum, the MyHC type IIA and IIX fibers fall somewhere in the middle, having intermediate properties ${ }^{10,59-61}$. Transition from slow-to-fast type and vice-versa is an important component of skeletal muscle plasticity 62 .

TWEAK appears to promote fast-type fibers in skeletal muscle. One of the key upstream regulators of skeletal muscle fiber composition, mitochondrial content, and oxidative metabolism is peroxisome proliferator-activated receptor gamma, coactivator 1 alpha (PGC-1 $\alpha)^{63,64}$. In muscle-specific transgenic mice 
that overexpress PGC-1 $\alpha$, there is a much higher proportion of Type I and Ila muscle fibers ${ }^{65}$. Our lab has found that TWEAK represses PGC-1a in skeletal muscle $^{66}$. In both extensor digitorum longus (EDL) and soleus muscles of TWEAK-Tg mice, we found that there was a significant reduction in type I myofibers with a concomitant increase in type II muscle fibers ${ }^{67}$. In stark contrast, the skeletal muscle of TWEAK-KO mice showed an increase in the proportion of type I fibers ${ }^{67}$. Additionally, subsarcolemmal and intermyofibrillar mitochondrial content was significantly increased in 5-month old TWEAK-KO mice, which was accompanied by improved exercise capacity compared to wild-type mice ${ }^{66}$. In addition, the skeletal muscle of TWEAK-KO mice showed a significant increase in the transcript levels of PGC-1 $\alpha$ and several other molecules related to oxidative metabolism ${ }^{66}$. These results were supported by similar findings in cultured myotubes treated with TWEAK ${ }^{66}$ and also in cardiomyocytes through the TWEAK-Fn14-TRAF2-canonical NF-kB pathway ${ }^{68}$.

Skeletal muscle is responsible for a majority of glucose disposal in the human body. Impairment in skeletal muscle glucose handling capacity leads to glucose and insulin intolerance. Recent studies in our laboratory have shown that with progressive age, skeletal muscle-specific TWEAK-Tg mice gain a considerably higher amount of body weight and fat mass compared to littermate control mice ${ }^{69}$. These mice also demonstrate glucose intolerance and insulin insensitivity. Increased levels of TWEAK inhibit AMPK and reduce the levels of glucose transporter type 4 (GLUT4), a major glucose transporter in skeletal muscle. Moreover, it was found that TWEAK represses the levels of Krüppel-like 
factor 15 (KLF15); myocyte enhancer factor 2 (MEF2), and PGC-1 $\alpha$, which are essential for the activation of the GLUT4 locus ${ }^{69}$. Collectively, these studies show the broad reach that TWEAK has in the regulation of skeletal muscle metabolic functions. Please refer to Figure 1.2 for a mechanistic summary and Figure 1.3 for a summary of TWEAK's physiological effects.

\section{TWEAK-Fn14 system and skeletal muscle atrophy}

Muscle wasting or atrophy is the result of a perturbation in proteostasis indicated by accelerated degradation of muscle proteins relative to the synthesis of new protein and is typically caused by reduced muscle tension in the case of disuse conditions or pathophysiology in a myriad of diseases. As a whole, muscle atrophy is characterized by a decrease in protein content, fiber diameter, force production, and fatigue resistance ${ }^{2}$. The TWEAK/Fn14 signaling axis has been shown to play a significant role in muscle atrophy through activation of the ubiquitin-proteasome system (UPS), autophagy-lysosomal system (ALS), and activation of caspases. However, blocking these downstream effector pathways does not completely ameliorate the atrophy phenotype, indicating that other mediators of skeletal muscle atrophy are at play.

One commonality among many catabolic conditions is the expression of two E3 ubiquitin ligases, MuRF1 and MAFBx. These two ligases label, via ubiquitination, specific target proteins for degradation by the 26S proteasome and are thought to be the drivers of muscle proteolysis ${ }^{70}$. Studies in our lab have identified TWEAK as a potent muscle-wasting cytokine even at low levels (10 
$\mathrm{ng} / \mathrm{ml}$ ) causing significant atrophy and promoting the degradation of creatine kinase and MyHC protein in cultured myotubes ${ }^{71}$. TWEAK activates NF-kB, which has been shown to be responsible for the upregulation of MuRF1 and targeted blocking of NF-KB significantly reduced the loss of MyHC and the atrophy phenotype as a whole ${ }^{72-74}$. TWEAK also causes muscle wasting in vivo where chronic administration of soluble TWEAK induced a significant reduction in body weight, skeletal muscle mass, and fiber cross-sectional area ${ }^{71} . \ln$ generating muscle-specific TWEAK transgenic $(\mathrm{Tg})$ mice, founders that expressed extremely high mRNA levels of TWEAK ( $>16$-fold increase) were discovered to have severe muscle loss and neonatal lethality ${ }^{71}$. Nonetheless, TWEAK-Tg mice expressing TWEAK mRNA at comparatively more moderate levels (4 - 6-fold increase) exhibited muscular atrophy and interstitial fibrosis, but without the neonatal lethality ${ }^{67}$. In support of the in vitro studies, TWEAK-Tg mice were shown to have elevated activation of NF-KB, increased expression of MuRF1, and ubiquitination of MyHC in skeletal muscle in naïve conditions ${ }^{67,71}$. In addition to the UPS, TWEAK has also been shown to elevate the expression of several components of autophagy-lysosomal system (ALS) ${ }^{75}$. In the ALS, a portion of the cytoplasm is partitioned off by a double-membrane autophagosome where ubiquitinated proteins, cellular debris, and organelles that may be too big or are unsuitable for degradation by the proteasome are trapped. Subsequently, the autophagosome fuses with the lysosome, where the contents of the vesicles are degraded ${ }^{76,77}$. It was discovered that several genes of the ALS were upregulated in conjunction with formation of autophagosomes in the skeletal 
muscle of mice after denervation or a period of starvation indicating that the ALS may play an important role in muscle atrophy ${ }^{37,78}$. In support of this finding, our lab has shown that several autophagy genes such as: Beclin1, LC3B, Atg5, and Atg12 are significantly increased in response to TWEAK treatment in cultured myotubes ${ }^{75}$. Additionally, in studies of TWEAK-treated myotubes that blocked NF-kB using adenoviral and shRNA techniques, the expression of Beclin1 was significantly reduced suggesting that the TWEAK-Fn14-NF-KB axis is involved in the activation of the $\mathrm{ALS}^{75}$.

The caspases, another important player in protein degradation, were also found to be upregulated in response to TWEAK ${ }^{75}$. MuRF1 of the UPS can ubiquitinate $\mathrm{MyHC}$, but it cannot complete this task unless the proteins are removed from the actomyosin complex. This would implicate other proteolytic systems such as the caspase system in the process of muscle atrophy, which has been demonstrated in catabolic conditions such as diabetes ${ }^{24}$. Activation of caspase- 3 was found to be imperative for this process and facilitated a $125 \%$ increase in protein degradation by the UPS ${ }^{24}$. Furthermore, after tibial denervation in caspase 3-KO mice, the gastrocnemius muscle weighed more and displayed a larger myofiber cross-sectional area when compared to wild-type mice $^{79}$. Studies from our lab have shown that TWEAK causes an increase in caspase-8 and caspase- 3 mRNA levels in C2C12 myotubes after 24 hours of treatment ${ }^{75}$. Caspase- 8 is responsible for activating pro-caspase- 3 to its activated, cleaved form. Elevated cleaved caspase-3 was evidenced by western blot analysis of $\mathrm{C} 2 \mathrm{C} 12$ myotubes in response to treatment with TWEAK ${ }^{75}$. 
Moreover, Z-VAD-FMK, a pan-caspase inhibitor, attenuated the degradation of MyHC in TWEAK-treated myotubes ${ }^{75}$. Collectively, these findings suggest that caspases are involved in TWEAK-induced muscle atrophy. However, it remains unknown whether the TWEAK-induced activation of caspases can also lead to skeletal muscle cell death in vivo and in vitro.

Even though TWEAK is an inflammatory cytokine, it was notable to find that TWEAK-Fn14 system mediates skeletal muscle atrophy in disuse conditions and during starvation, which generally do not involve any overt inflammatory response ${ }^{67,80-82}$. Levels of Fn14, but not TWEAK, are increased in skeletal muscle in disuse conditions such as denervation or immobilization. The role of the TWEAK-Fn14 system in skeletal muscle atrophy was confirmed by the findings that denervation- or starvation-induced loss of skeletal muscle mass is inhibited in TWEAK-KO mice ${ }^{67,80}$. Conversely, TWEAK-Tg mice showed increased loss of skeletal muscle mass in response to denervation compared to littermate control mice ${ }^{67}$. Consistent with studies in cultured myotubes, TWEAKFn14 signaling increases NF-kB and expression of MuRF1 in denervated skeletal muscle of mice ${ }^{67}$.

Our recent studies have also demonstrated that TWEAK represses the expression of PGC-1 $\alpha$ in cultured primary myotubes and in denervated skeletal muscle of mice ${ }^{66,83}$. Overexpression of PGC-1a rescues TWEAK-induced atrophy and activation of NF-kB and the components of UPS in cultured myotubes. Furthermore, progressive muscle atrophy in TWEAK-Tg mice is significantly attenuated in TWEAK-PGC-1 $\alpha$ double Tg mice suggesting that PGC- 
1a plays an important role in TWEAK-induced muscle atrophy ${ }^{83}$. Furthermore, our studies have provided evidence that there are reciprocal interactions between TWEAK-Fn14 and PGC-1 $\alpha$ in denervated muscle. While TWEAK-Fn14 signaling represses the expression of PGC-1 $1 \alpha$, transgenic overexpression of PGC-1a inhibits the expression of Fn14 in denervated skeletal muscle of mice ${ }^{83}$. Please refer to Figure 1.2 for a mechanistic summary and Figure 1.3 for a summary of TWEAK's physiological effects.

\section{Apoptosis}

Apoptosis and necroptosis are two modes of "programmed" cell death which play important roles during embryonic development, morphogenesis, ontogeny, and proper functioning of the immune system through regulating cell turnover and removal of harmful cells. Apoptosis involves cell membrane blebbing, volume contraction, nuclear condensation, and endonucleolytic cleavage of DNA ${ }^{84}$. This should not be confused with necrosis or necroptosis due to various differences mechanistically and molecularly, but the most obvious is that apoptosis results in the "orderly parceling" of cellular contents that are then phagocytosed and do not initiate an inflammatory response ${ }^{85,86}$. Conversely, necroptosis is the "lesscontrolled" process where intrinsic factors poke holes in the cell membrane, releasing cellular contents, and initiating a subsequent inflammatory response ${ }^{87}$. These two processes are independent, but can occur sequentially or concomitantly ${ }^{87}$. 
Apoptosis relies on the downstream activation of catalytically inactive cysteine proteases known as caspases. Activation of the caspases and initiation of apoptosis can occur through intrinsic or extrinsic pathways. In the intrinsic pathway, the state of the mitochondria determines whether or not the apoptotic program is initiated. Normally, apoptosis is actively suppressed and maintained until a negative stimulus such as the absence of growth factors or hormones, reactive oxygen species (ROS), cytokines, and other insults upset the balance of anti- and pro-apoptotic molecules ${ }^{87}$. The general paradigm consists of changes to the inner mitochondrial membrane that result in the opening of the mitochondrial permeability transition (MPT) pore, subsequent loss of transmembrane potential, and release of pro-apoptotic proteins that are normally sequestered in the intermembrane space ${ }^{87,88}$. Among these, there appears to be a first wave of pro-apoptotic proteins followed by a second wave once the cell has committed to an apoptotic fate.

The first wave consists of cytochrome c, Smac/DIABLO, and $\mathrm{HtrA2/Omi87,88}$. Collectively, the downstream signaling of these molecules leads to the mitochondrial caspase-dependent pathway, requiring the formation of an "apoptosome" and the degradation of inhibitors of apoptosis proteins (IAP). The "apoptosome" is formed when cytochrome c binds to apoptotic protease activating factor-1 (Apaf-1), which then leads to the binding of procaspase- 9 resulting in its activation to caspase- $9^{87,88}$. However, Smac/DIABLO and HtrA2/Omi need to be released to inhibit IAPs and promote a pro-apoptotic milieu $^{89,90}$. Activated caspase- 9 cleaves procaspase-3 to the active caspase- 3 , 
which then executes the apoptotic program. In contrast to the first wave, the second wave of proteins are responsible for chopping up the DNA and consists of apoptosis inducing factor (AIF), endonuclease $G$, and $C A D^{87}$. The initiation of mitochondrial release of pro-apoptotic proteins relies on the B-cell lymphoma (Bcl-2) family.

The Bcl-2 family of 25 genes are subdivided into anti-apoptotic and proapoptotic proteins and are the factors responsible for the suppression or commitment of the mitochondria to apoptosis through regulation of mitochondrial membrane permeability. Some of the anti-apoptotic proteins include: Bcl-2, Bcl-x, $\mathrm{Bcl}-\mathrm{XL}, \mathrm{Bcl}-\mathrm{XS}, \mathrm{Bcl}-\mathrm{w}, \mathrm{BAG}$, and some of the pro-apoptotic proteins include: $\mathrm{Bcl}-$ 10, Bax, Bak, Bid, Bad, Bim, Bik, and Blk ${ }^{87}$. In general, the balance between these two groups determines the fate of the cell with intrinsic stress promoting the activation of the pro-apoptotic group ${ }^{91}$.

The extrinsic pathway typically relies on the binding of a protein ligand to a transmembrane death receptor (DR) that initiates the pro-apoptotic cascade. Members of the TNFRSF are among those that have been deemed DRs due to the conserved death domain (DD) sequence on their cytoplasmic tail. The DRs include: Fas, TNFR1, DR3, TNF-related apoptosis-inducing ligand (TRAIL) (TRAIL-R1 or DR4, and TRAIL-R2 or DR5), and DR6. The receptor DD allows for the recruitment of other protein molecules that have a DD of their own as well as a death-effector domain at their $\mathrm{N}$-terminus. An example of this is the wellcharacterized Fas-associated death domain (FADD) protein ${ }^{92,93}$. The deatheffector domain of FADD recruits procaspase-8 to the Fas-signaling complex, 
subsequently activating caspase- 8 , which then initiates the catalytic cleavage of procaspase- 3 to the active, cleaved caspase- 3 . Cleaved caspase- 3 is the main effector caspase in both apoptotic pathways and degrades many proteins leading to the characteristic phenotype of apoptosis. One protein that cleaved caspase-3 targets is the inhibitor of caspase-activated deoxyribonuclease (ICAD), which is bound in complex to CAD, an endogenous endonuclease, resulting in DNA degradation and eventual cell death ${ }^{94,95}$.

Although skeletal muscle cells generally do not die during atrophy, selective myonuclear apoptosis has been found to contribute to muscle wasting in at least some atrophy conditions, such as aging and denervation ${ }^{96-99}$. Activation of some caspases can also induce protein degradation independent of apoptosis as described above ${ }^{34,100-102}$. Interestingly, the TNFRSF member Fn14 does not have a DD, but does have a TRAF binding domain on its cytoplasmic tail that can bind TRAF2 ${ }^{40,46,47}$. TWEAK signaling through the Fn14 receptor is known to activate both canonical and non-canonical NF-kB pathways and to upregulate proteins of the UPS, the ALS, and the caspase system causing severe muscle atrophy in response to TWEAK treatment ${ }^{53,54}$. Nakayama et al. provided evidence that TWEAK-Fn14 signaling induced substantial levels of caspase- 3 and caspase- 8 protein in immune cells showing that the TWEAK-Fn14 signaling axis had the ability to cause caspase-dependent apoptosis ${ }^{103}$. Additionally, when TWEAK-treated cells were pre-treated with the pan-caspase inhibitor Z-VAD-FMK, there was a significant increase in reactive oxygen intermediates (ROI) and a subsequent shift to a necrotic phenotype ${ }^{103}$ indicating 
that TWEAK-Fn14 signaling can mediate multiple death pathways. In their discussion, they likened the Fn14 receptor to TNFR2 ${ }^{103}$. However, the signaling mechanisms for the TWEAK-Fn14 upregulation of caspases and the role that apoptosis may play in in TWEAK-induced loss of skeletal muscle mass remain enigmatic.

\section{Necroptosis}

Another form of programmed cell death is necroptosis in which receptor interacting protein (RIP) kinases play critical roles. The RIP kinases are a key regulator at the heart of many cellular fate decisions with the ability to not only signal cell-survival through activation of NF-KB, but also to signal cell death through apoptosis and necroptosis ${ }^{104}$. RIPs are a family of seven serine/threonine kinases with RIP1 being the most well studied member to date in the context of DRs, such as Fas and TNFR $1^{105}$. The differential signaling pathways activated by RIP1 have been divided into the pro-survival complex I, the apoptotic complex II, and the necroptotic complex IIB ${ }^{104}$. The membranebound complex I is formed in response to TNF signaling and results in RIP1 being recruited to TNFR1 by TRADD (TNFR1-associated death domain), which acts as an assembly platform, recruiting TRAF2 as well ${ }^{104}$. Ultimately, this leads to the activation of NF-KB and transcription of pro-survival genes such as clAPs and cFLIP (Cellular FLICE (FADD-like IL-1 $\beta$-converting enzyme)-inhibitory protein). Interestingly, the question that still remains is how does a protein switch from having a pro-survival role to one that initiates cell death. 
It is thought that post-translational modifications to RIP1 and to other members of complex I lead to the dissociation of complex I from TNFR1, resulting in cytoplasmic localization. This is followed by recruitment of FADD and the subsequent processing of procaspase- 8 to activated caspase- $8^{106}$. If prosurvival NF-KB signaling is successful, it is suggested that CIAP and cFLIP inhibit apoptosis by preventing caspase-8 from executing caspase-3 mediated apoptosis $^{106-108}$. In the event of viral inhibition of the caspase system, the necrosome is formed, serving as an additional layer of redundancy ensuring that the cell death process is successful.

The necrosome in complex IIB is formed by the association of FADD, RIP1, and RIP3. Unlike its role in complex I and II, the kinase activity of RIP1 is required for the execution of necroptosis ${ }^{109}$. Furthermore, RIP1-RIP3 transphosphorylation is also necessary for necroptosis to proceed ${ }^{110}$. Following activation, the pseudokinase mixed-lineage kinase domain-like protein (MLKL) is phosphorylated by RIP3, which effectively activates the necrosome ${ }^{111}$. MLKL targets phosphatidylinositol phosphates (PIPs), cardiolipin (CL) and phosphatidylglycerol (PG) and subsequently punches holes in the cellular membranes leading to membrane rupture and organelle swelling, the hallmark morphological characteristics of necroptosis ${ }^{111}$.

\section{Regulation of Redox Homeostasis}

Reactive oxygen species (ROS) have been associated with a diverse array of signaling functions in both physiological and pathophysiological states. The 
production of ROS is a normal part of cellular metabolism with some tissues being more metabolically active than others. When the production of ROS exceeds the cell's ability to process and defend itself from the cytotoxic effects of ROS, this leads to a state of oxidative stress that can result in tissue injury. Oxidative stress has been associated with many chronic disease states including diabetes mellitus ${ }^{112}$, Alzheimer's disease, amyotrophic lateral sclerosis (ALS), and Duchenne muscular dystrophy ${ }^{113}$ to name just a few.

ROS consist of oxygen-centric chemicals whose properties make them particularly prone to reacting with and changing the chemical nature of otherwise stable molecules. This group consists of the superoxide radical $\left(\mathrm{O}_{2}{ }^{\circ}\right)$, the highly reactive hydroxyl radical $(\cdot \mathrm{OH})$, and hydrogen peroxide $\left(\mathrm{H}_{2} \mathrm{O}_{2}\right)$. Superoxide radicals are generated in several different locations within the cell including the mitochondria by the electron transport chain, the cellular membranes by NADPH oxidase (NOX) enzymes, the cytosol by enzymes such as xanthine oxidase (XO), and even extracellularly by phagocytes in response to injury and inflammation ${ }^{112,114,115}$. Along the continuum of reactivity, superoxide is relatively stable and can act as a weak oxidizing agent, but more importantly it is a source for the production of hydroxyl radicals and hydrogen peroxide ${ }^{112}$. Superoxide radicals are able to produce these by liberating iron from iron-containing proteins (ferritin ${ }^{116}$, hemoglobin, myoglobin) for the Fenton reaction, creating the volatile hydroxide radical ${ }^{114,115}$.

$\mathrm{O}_{2}{ }^{\cdot}+\mathrm{Fe}(\mathrm{III}) \rightarrow \mathrm{Fe}(\mathrm{II})+\mathrm{O}_{2}$ and then, $\mathrm{Fe}(\mathrm{II})+\mathrm{H}_{2} \mathrm{O}_{2} \rightarrow{ }^{\cdot} \mathrm{OH}+\mathrm{OH}^{-}+\mathrm{Fe}(\mathrm{III})$ 
Another reaction that superoxide radicals partake in is with the nitric oxide radical (NO) creating the powerful oxidant peroxynitrite $\left.\left(\mathrm{ONO}_{2}\right)^{-}\right)^{115}$. On the other hand, hydrogen peroxide is a stable molecule with the ability to readily diffuse across membranes and to act as a signaling molecule; whereas, hydroxyl radicals have a very short half-life, react instantaneously and indiscriminately with most biological molecules, and result in the propagation of toxic free radical chain reactions ${ }^{112,114}$. ROS act as signal transducers regulating diverse downstream signaling pathways in addition to their role in the oxidation of macromolecules resulting in cytotoxicity.

The reason that ROS have received so much attention over the years is due to their ability to cause oxidative damage to macromolecules. Lipid peroxidation and the oxidation of DNA have received the most attention, but the oxidation of enzymes through the addition of carbonyl groups can wreak havoc on proteins as well ${ }^{12,114}$. In the process of lipid peroxidation, reactive free radicals such as the hydroxyl radical can abstract a hydrogen from the methylene $\left(-\mathrm{CH}_{2}-\right)$ group of a fatty acid creating a carbon radical $\left(-{ }^{*} \mathrm{CH}-\right)$ that rearranges itself to a diene and then binds to molecular oxygen to form a peroxyl radical ${ }^{112,114}$. Ultimately, the peroxyl radical reacts with other lipids resulting in a chain reaction that can change the overall membrane properties of the organelle or cell. In addition, hydroxyl radicals can attack the deoxyribose sugar as well as the purine and pyrimidine bases of DNA leading to single/double-strand breaks and protein-DNA crosslinks ${ }^{112,114}$. Collectively, if oxidative stress is pervasive 
enough and the cell is unable to repair the damage, apoptosis or necrosis is initiated. So, how do cells protect themselves from oxidative damage?

Cells maintain a number of antioxidant defense systems that reduce ROS to non-reactive intermediates, thereby limiting their capacity to cause oxidative damage. The most famous of these is the three-member family of superoxide dismutase (SOD) enzymes, each of which have a specific subcellular localization and each house specific metal cations capable of dismutating superoxide into molecular oxygen and hydrogen peroxide. SOD1 (Cu-Zn-SOD) is localized to the cytosol and mitochondrial intermembrane space, while SOD2 (Mn-SOD) is localized to the mitochondrial matrix ${ }^{117,118}$. SOD3 or extracellular SOD also contains $\mathrm{Cu}$ and $\mathrm{Zn}$, but is localized to the extracellular milieu ${ }^{117}$. The importance of these SOD enzymes is highlighted by the association of mutations in SOD1 with familial ALS and lethal cardiomyopathy induced by knocking out SOD2 in mice ${ }^{117}$. After dismutation, hydrogen peroxide can be converted to water and molecular oxygen by catalase, which is localized to peroxisomes in close proximity to the mitochondria ${ }^{114}$. A similar function is achieved by the glutathione peroxidase (GPx), peroxiredoxin (Prx), and thioredoxin (Trx) enzymes that function as reducing agents. These are just a few of the more well-known antioxidant enzymes, with others being upregulated by the transcription factors Nrf-2 and Ref- $1^{119}$. Nrf-2 is activated by the disassociation of the KEAP1 protein in response to excessive ROS, acting as a redox sensor. This frees up Nrf-2 to bind to antioxidant response element (ARE) promoters on DNA leading to transcription of additional antioxidant enzymes. 


\section{Oxidative Stress in Skeletal Muscle}

With skeletal muscle being the largest and one of the most metabolically active tissues, it is imperative that the production of ROS be counterbalanced by antioxidant defenses to maintain cellular homeostasis. Initially, ROS were thought to be mediators of disease and high hopes were placed on treating these diseases with high doses of exogenous antioxidants. With mixed results, further research over the years has shown the importance of ROS and redox signaling in normal physiology. Paradoxically, skeletal muscle fibers produce ROS in response to exercise training ${ }^{120,121}$, which makes intuitive sense, but also produce ROS in response to long periods of disuse ${ }^{122,123}$. This places ROS production and possibly oxidative stress at the heart of anabolic adaptive responses and catabolic atrophic responses in skeletal muscle.

The sources of ROS in skeletal muscle are the mitochondria, xanthine oxidase (XO), and NADPH oxidases (NOXs), with NOX2 and NOX4 being the homologues expressed in muscle. The multi-component NOX2 complex is found in the transverse tubule membrane, sarcoplasmic reticulum, and sarcolemma with evidence showing NOX2 as one of the major sources of ROS under resting and contracting conditions ${ }^{124-127}$. During exercise training, there is an increase in cytosolic ROS production with a subsequent increase in the antioxidant enzymes, SOD2, GPx, and catalase ${ }^{127}$. By inhibiting NOX2, there is a reduction in the adaptive gene expression that is typically upregulated in response to endurance exercise and is thought to be due to the ROS-dependent regulation of 
calcium-controlled signaling cascades ${ }^{128}$. Additionally, mitochondrial biogenesis is a well-known adaptive response that occurs in response to exercise training through the upregulation of the transcription factor PGC1- $\alpha$. ROS have been shown to upregulate PGC1- $\alpha^{129}$, while dietary antioxidants have been shown to block exercise-induced mitochondrial biogenesis. This suggests that ROS are important for mitochondrial adaptation to exercise ${ }^{130}$. Insulin-dependent glucose uptake $^{124,131}$ and the translocation of GLUT4 ${ }^{131}$ are two other areas where ROS have been shown to be play a major role in muscle homeostasis. Collectively, these suggest that ROS are essential for normal muscle physiology. However, when the production of ROS exceeds the ability of the muscle to ameliorate their toxic effects, this can lead to negative consequences.

Some of these negative consequences in response to excess ROS can amount to nothing more than the fatigue that one feels after strenuous exercise $^{132}$ or can greatly accelerate the degradation of one's quality of life in the case of Duchenne muscular dystrophy ${ }^{124}$. Redox disturbances can play a primary role in disease such as in the inherited defect to reductase selenoprotein $\mathrm{N}$ (SEPN1) that leads to chronic oxidative stress in SEPN1-related myopathy ${ }^{133}$ or a secondary role as in the case of Duchenne muscular dystrophy ${ }^{124}$. Under catabolic conditions like these, cytokines are one of the major mediators of muscle atrophy. TNF- $\alpha$ is known to cause an increase in ROS production and initiates oxidative stress in the process of cell death ${ }^{134}$. A recent study on macrophages found that TWEAK/Fn14 signaling results in an increase in ROS produced in a NOX2 dependent manner, ${ }^{135}$ which is one of the major producers 
of ROS in skeletal muscle. Furthermore, previous analysis of microarray data from our lab suggests that one of the pathways affected by TWEAK in myotubes is that of oxidative stress ${ }^{136}$. Despite this, the relationship between TWEAK and oxidative stress remains poorly understood and has not been investigated in skeletal muscle.

\section{Purpose and Hypothesis}

Despite the quantum leap in our understanding of the TWEAK-Fn14 signaling axis and the downstream effector pathways, there are still many questions that need to be addressed. Of these, it remains unknown whether TWEAK can induce cell death through apoptosis or necroptosis. It is notable that TWEAK mediates skeletal muscle wasting in response to denervation and during aging, a condition which also involves loss of neuromuscular junctions. There are reports suggesting that selective myonuclear apoptosis occurs in these conditions leading to a net loss of skeletal muscle mass. Furthermore, oxidative stress has been implicated in skeletal muscle weakness and atrophy. However, it remains unknown whether TWEAK can induce apoptosis and oxidative stress in skeletal muscle. I hypothesize that the TWEAK/Fn14 axis signals cell death in an alternative extrinsic apoptotic pathway similar to TNFR2 and that TWEAK induces oxidative stress providing an additional mechanistic component that enhances the accelerated protein degradation in skeletal muscle in catabolic conditions. 


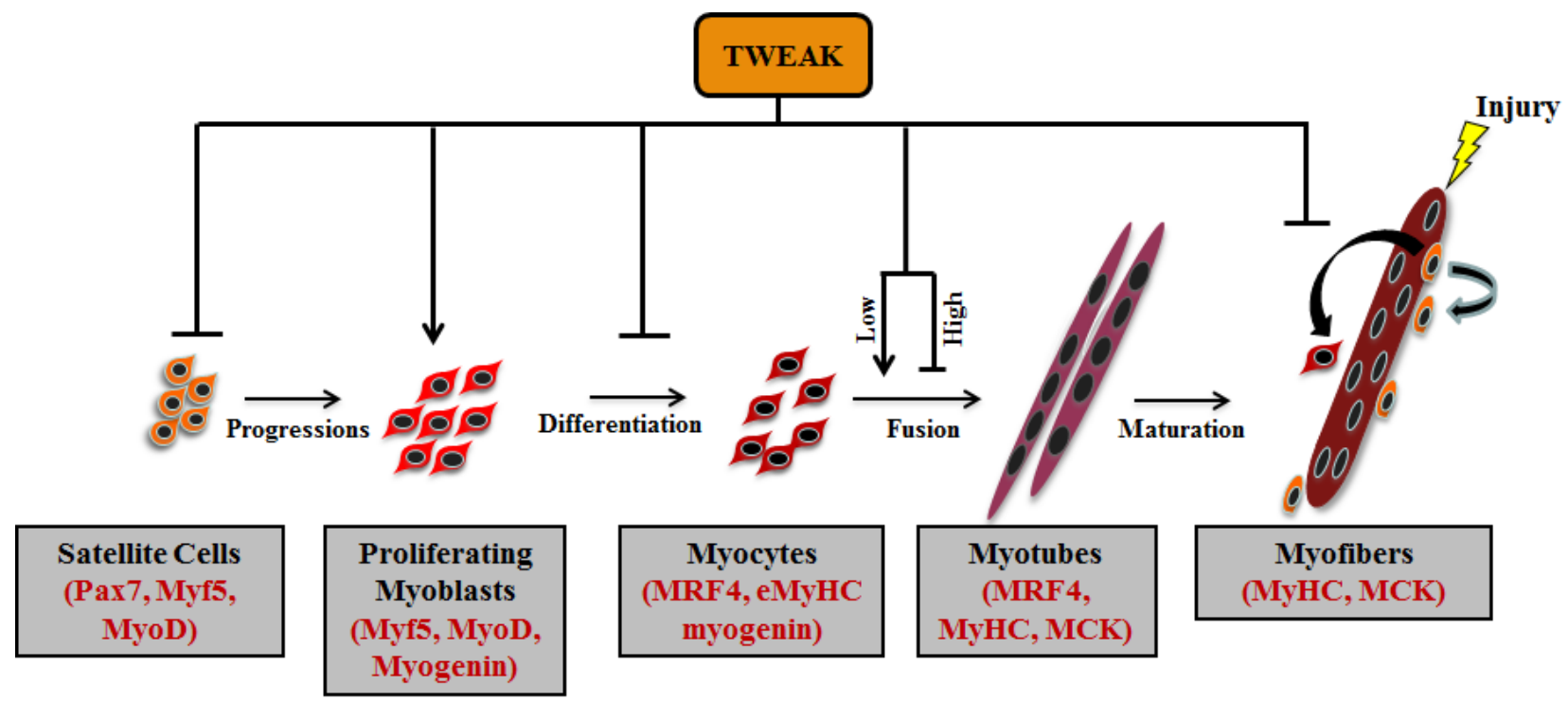

Figure 1.1: TWEAK's effect on myogenesis. Satellite cells undergo myogenic commitment, producing myoblasts. TWEAK inhibits the self-renewal of satellite cells in favor of myogenic commitment and proliferation of myoblasts. At higher concentrations, TWEAK inhibits the differentiation of myoblasts. Low concentrations of TWEAK promote fusion of myocytes into myotubes; whereas, high concentrations of TWEAK inhibit this process. In response to chronic disease, TWEAK abates myofiber regeneration. Transcription factors expressed at each stage of myogenesis are listed in red font. 


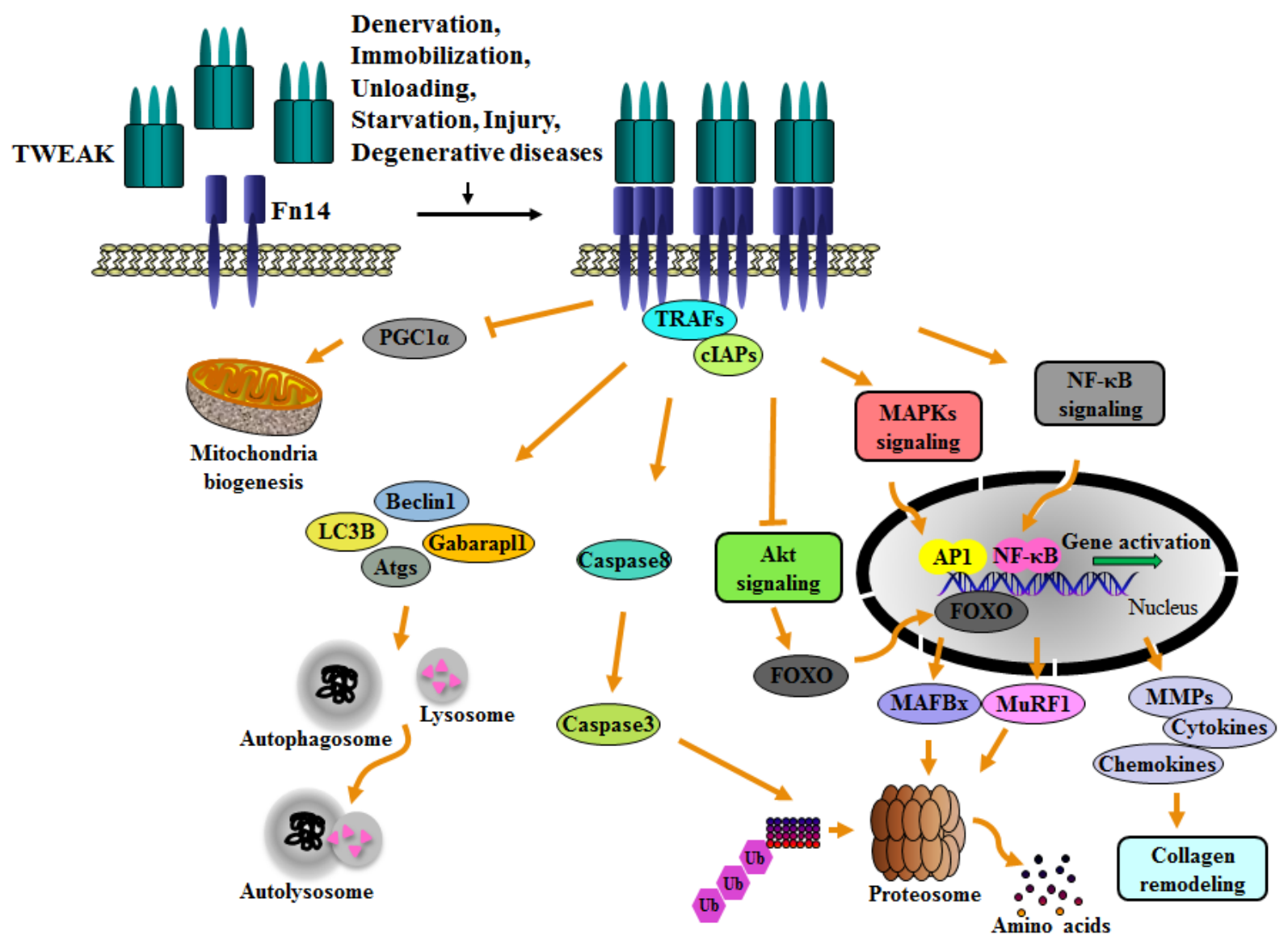

Figure 1.2: Schematic illustration of TWEAK and downstream signaling

cascades. The Fn14 receptor is upregulated on skeletal muscle in response to injury or in disuse conditions, providing substrate for trimeric TWEAK to bind. This leads to the recruitment of various TRAFs and clAPs that lead to a myriad of downstream signaling cascades. TWEAK inhibits PGC-1 $1 \alpha$, resulting in a decrease in mitochondrial biogenesis. TWEAK elevates the expression of various components of the autophagy lysosomal system (ALS) and promotes the activation of the ubiquitin proteasome system (UPS) by stimulating the NF-KB pathway and inhibiting Akt signaling. Inhibition of Akt also results in the activation of the Foxo family of transcription factors, leading to proteosomal degradation of 
muscle proteins through increased expression of MAFBx and MuRF1. In addition, the TWEAK-Fn14 system activates the MAPK signaling cascades resulting in the binding of AP-1 transcription factor to DNA and the expression of genes such as: cytokines, chemokines and MMPs which contribute to collagen remodeling and fibrosis. TRAF, TNF-receptor associated factor; cIAP, cellular inhibitor of apoptosis; AP1, activator protein-1; FOXO, Forkhead box O. 


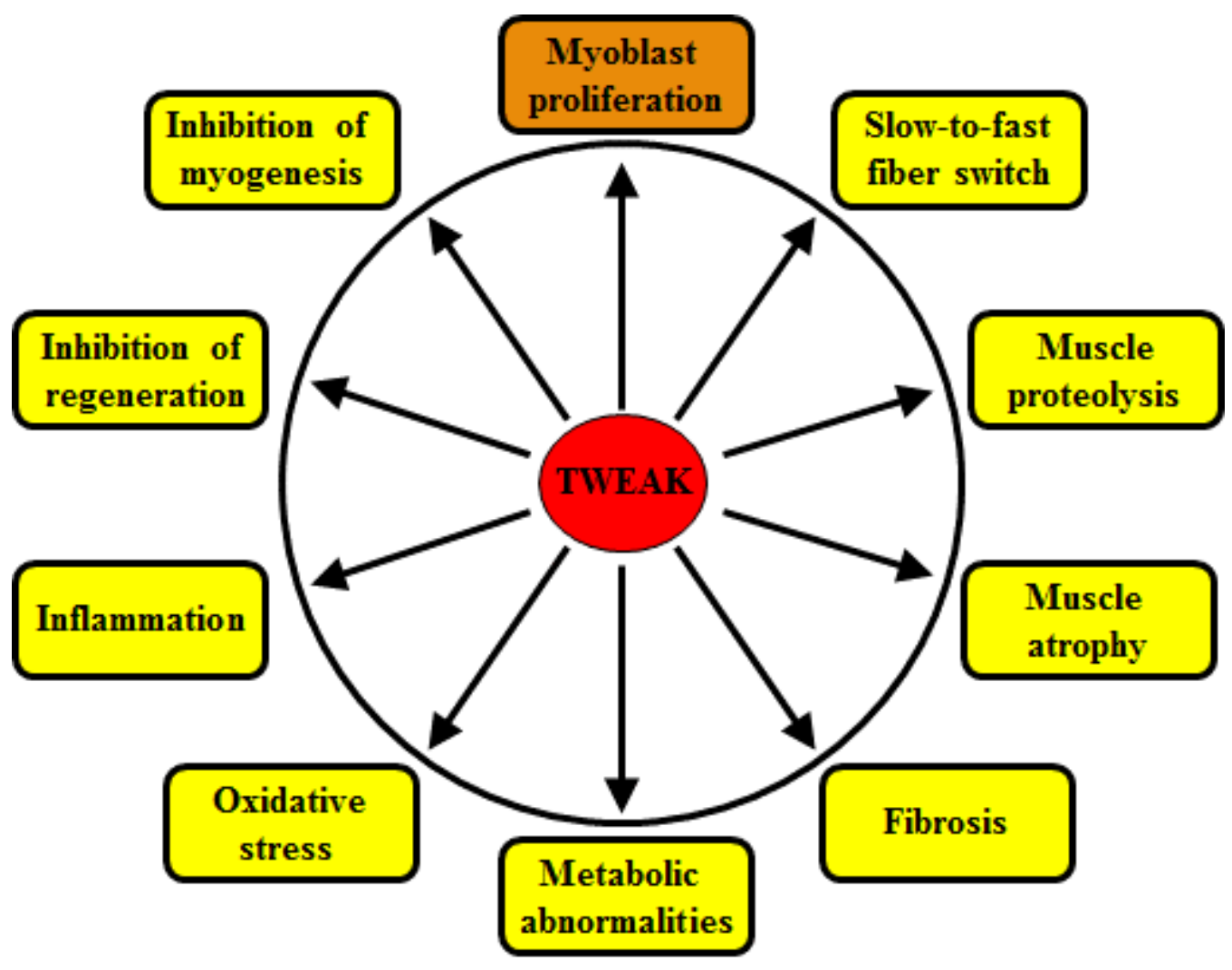

Figure 1.3: Physiological Effects of TWEAK. TWEAK-Fn14 signaling results in a number of physiologically relevant consequences from muscle proteolysis and atrophy to oxidative stress and inflammation in different conditions. 


\section{CHAPTER 2: MATERIALS AND METHODS}

\section{Mice}

Mice (strain: C57BL6) were purchased from Jackson Laboratory (Bar Harbor, ME, USA). TWEAK-KO mice were provided by A. Ashkenazi ${ }^{137}$. The genotype was confirmed by PCR utilizing tail DNA. Mice were housed and fed in stainless steel cages on a 12 hour on and 12 hour off lighting schedule.

Sciatic denervation was performed by anesthetizing the mice with an intraperitoneal injection of 2,2,2 tribromoethanol (Aldrich T4, 840.2 or equivalent) at a concentration of $0.2 \mathrm{ml} / 10$ grams of body weight. Anesthesia was confirmed with lack of response to a toe pinch. The mouse hindlimbs were shaved and an $\sim 0.5 \mathrm{~cm}$ incision was made proximal to the pelvis and the medial side of the right leg. The muscles were separated with forceps and the sciatic nerve was lifted out with a surgical hook. A 2-3mm section of the sciatic nerve was removed and the incision was closed using surgical sutures. A sham denervation was performed on the contralateral leg with an $\sim 0.5 \mathrm{~mm}$ incision followed by separation of muscles. The incision was then closed utilizing surgical sutures. The mice were allowed to recover for three days in their respective cages. On the third day, the mice were euthanized by cervical dislocation and the tibialis anterior, gastrocnemius, and soleus muscle were removed for subsequent analysis. All experimental protocols with mice were in accordance with approved ethical 
guidelines of the Institutional Animal Care and Use Committee at the University of Louisville.

\section{Mouse Primary Myoblast Isolation}

C57BL6 mice were euthanized and the hind limb muscles were isolated. Excess connective tissues and fat were cleaned in sterile PBS followed by mincing into coarse slurry and enzymatically digested at $37^{\circ} \mathrm{C}$ for $1 \mathrm{~h}$ by adding $400 \mathrm{IU} / \mathrm{ml}$ collagenase II (Worthington). The digested slurry was then spun, pelleted and triturated several times and passed through a 70- $\mu \mathrm{m}$ and then 30$\mu \mathrm{m}$ cell strainer (BD Falcon). The filtrate was spun at 1,000g and suspended in myoblast growth medium (Ham's F-10 medium with 20\% FBS supplemented with $10 \mathrm{ng} / \mathrm{ml}$ of basic fibroblast growth factor). Cells were first refed after 3 days of initial plating. For the first few passages, cells were also enriched by pre-plating for removal of fibroblasts and selection of a pure myoblast population.

\section{Cell Culture}

Purified mouse primary myoblasts were plated in myoblast growth medium consisting of Ham's F-10 Nutrient Mix supplemented with 20\% FBS, 1\% Penicillin-Streptomycin (Gibco), and $10 \mathrm{ng} / \mathrm{ml}$ of basic fibroblast growth factor (Peprotech). Upon reaching a cellular confluence of $\sim 85-90 \%$, the growth medium was replaced with differentiation medium consisting of Dulbecco's Modified Eagle's Medium (ATCC) supplemented with 2\% horse serum (Gibco) and $1 \%$ Penicillin-Streptomycin (Gibco). The cells were allowed to fully 
differentiate for 72 hours with replenishment of differentiation medium every 48 hours.

\section{RNA Isolation and quantitative real-time PCR}

RNA was isolated from cultured myotubes or mouse skeletal muscle using the RNeasy Mini Kit (Qiagen). The RNA in each sample was measured using the NanoDrop instrumentation (NanoDrop Technologies). To synthesize cDNA, $1 \mu \mathrm{g}$ of purified RNA was utilized in conjunction with the High-Capacity cDNA Reverse Transcription Kit (Applied Biosystems). Primers for qRT-PCR were designed using Vector NTI Xi software (Invitrogen). The sequences for all primers can be found in Table 1.

Table 1. Sequence of the primers used for QRT-PCR assay.

\begin{tabular}{|l|l|l|}
\hline $\begin{array}{c}\text { Gene } \\
\text { name }\end{array}$ & \multicolumn{1}{|c|}{ Forward Sequence } & \multicolumn{1}{c|}{ Reverse Sequence } \\
\hline SOD1 & 5'-TGAACCAGTTGTGTTGTCAG-3' & 5'-TCCATCACTGGTCACTAGCC-3' \\
\hline SOD2 & 5'-TGGCTTGGCTTCAATAAGGA-3' & 5'-AAGGTAGTAAGCGTGCTCCCACAC-3' \\
\hline SOD3 & 5'-AGGTGGATGCTGCCGAGAT-3' & 5'-TCCAGACTGAAATAGGCCTCAAG-3' \\
\hline GPX1 & 5'-GGGCTCCCTGCGGGGCAAGGT-3' & 5'-ATGTACTTGGGGTCGGTCATG-3' \\
\hline GPX3 & 5'-TCTCAAGTATGTTCGACCAGGTGG-3' & 5'-TCCCCGTTCACATCTCCTTT-3' \\
\hline CAT & 5'-CGCCACATGAATGGCTATGGATC-3' & 5'-AAGCCTTCCTGCCTCTCCAACA-3' \\
\hline XDH & 5'-ATCTGGAGACCCACTGCACC-3' & 5'-TGTGCTCACGAAGAGCTCCAT-3' \\
\hline NOX2 & 5'-AGTGTGTCGAAATCTGCTCTCCTT-3' & 5'-TACTCTTCGTTCTCATTGTCACCG-3' \\
\hline$\beta$-actin & 5'-CAGGCATTGCTGACAGGATG-3' & 5'-TGCTGATCCACATCTGCTGG-3' \\
\hline
\end{tabular}

Quantification of mRNA was done using the SYBR Green method on ABI Prism 7300 Sequence Detection System (Applied Biosystems). The thermal conditions consisted of an initial denaturation at $95^{\circ} \mathrm{C}$ for $10 \mathrm{~min}$ followed by 40 cycles of denaturation at $95^{\circ} \mathrm{C}$ for $15 \mathrm{~s}$, annealing and extension at $60^{\circ} \mathrm{C}$ for 1 minute and a final step melting curve of $95^{\circ} \mathrm{C}$ for $15 \mathrm{~s}, 60^{\circ} \mathrm{C}$ for $15 \mathrm{~s}$ and $95^{\circ} \mathrm{C}$ for $15 \mathrm{~s}$. All 
reactions were carried out in duplicate to reduce variation. The results were exported to Microsoft Excel for further analysis. Data normalization was accomplished using the endogenous control $\beta$-actin and the normalized values were subjected to a $2^{-\Delta \Delta C t}$ formula to calculate the fold change between the control and experimental groups.

\section{$\underline{\text { Western Blot }}$}

Quantitative estimation of various proteins was done by performing a western blot. Cultured myotubes were trypsinized followed by centrifugation at $3500 \mathrm{rpm}$. The pellet was washed with PBS and lysed in lysis buffer $(50 \mathrm{mM}$ Tris-Cl $(\mathrm{pH}$ 8.0), $200 \mathrm{mM} \mathrm{NaCl}, 50 \mathrm{mM} \mathrm{NaF}, 1 \mathrm{mM}$ dithiotheritol, $1 \mathrm{mM}$ sodium orthovanadate, $0.3 \%$ IGEPAL and protease inhibitors). Approximately, $100 \mu \mathrm{g}$ of protein was resolved on each lane on $10 \%$ SDS-polyacrylamide gel electrophoresis, electrotransferred onto nitrocellulose membrane, and probed using specific antibodies and detected by chemiluminescence (Bio-Rad). Approximate molecular masses were determined by comparison with the migration of pre-stained protein standards (Bio-Rad).

\section{Flow Cytometry}

Apoptosis was assessed by Annexin V/PI staining followed by FACS according to the manufacturer's instructions (BD Biosciences). In brief, myotubes were collected and washed with PBS and then resuspended in 1X binding buffer. $100 \mu \mathrm{l}$ containing $\sim 1 \times 10^{5}$ cells were then transferred to test tubes. As control 
groups, there were unstained cells, cells stained with Annexin $V$ alone, and cells stained with $\mathrm{PI}$ alone in addition to the experimental groups incubated in both stains. The tubes were incubated at room temperature in the dark for 15 mins. Subsequent FACS analysis was performed on a C6 Accuri cytometer (BD Biosciences) equipped with two lasers.

\section{Lactate Dehydrogenase (LDH) Assay}

The amount of LDH in culture supernatants was measured using an LDH Cytotoxicity Assay kit following the protocol suggested by the manufacturer (Thermo Scientific).

\section{Oxidative Stress Probe}

For the detection of oxidative stress, TWEAK-treated myotubes were incubated with CellROX deep red reagent (Life Technologies) according to manufacturer instructions with minor modification to the incubation period for 45 mins at $37^{\circ} \mathrm{C}$ rather than the 30 mins. Cultured myotubes were then counterstained with Hoechst 33342 (Life Technologies) and visualized with a Nikon Eclipse TE 2000-U microscope (Nikon). Equivalent contrast adjustments were made using ImageJ software.

\section{Statistical Analysis}

All experimental protocols with mice were in accordance with approved ethical guidelines of the Institutional Animal Care and Use Committee at the 
University of Louisville. Statistical analyses used two-tailed Student's t-test to compare quantitative data populations with normal distribution and equal variance. A value of $P<0.05$ was considered statistically significant unless otherwise specified. 


\section{CHAPTER 3: RESULTS}

The major goal of my project was to investigate whether TWEAK induces skeletal muscle death and whether oxidative stress plays a role in TWEAK-induced cytotoxicity.

\section{TWEAK induces cytotoxicity in mouse primary myotube cultures. TWEAK} has been shown to induce muscle atrophy both in vivo and in vitro $66,67,71,75,82,138$ 140. We investigated whether TWEAK also affects the survival of cultured myotubes. We first established primary myoblast cultures from C57BL6 mice. At $90 \%$ confluency, the medium of the cells was changed to differentiation medium, (DM) which led to the formation of multinucleated myotubes by $72 \mathrm{~h}$. The myotube cultures were then treated with increasing amounts of soluble TWEAK protein. As shown in Figure 3.1A, the number of myotubes were significantly reduced in TWEAK-treated cultures compared to controls.

Lactate dehydrogenase (LDH), is a soluble yet stable enzyme found inside every living cell. When the cell membranes are compromised or damaged in any way, $\mathrm{LDH}$ is released into the surrounding extracellular space. The presence of $\mathrm{LDH}$ in the culture medium is routinely used as a cell death marker and the relative amounts of live and dead cells within the medium can be quantitated by measuring the amount of released LDH using a colorimetric or fluorometric 
assay. To quantify TWEAK cytotoxicity on myotubes, we treated primary myotube cultures with soluble 10 or $100 \mathrm{ng} / \mathrm{ml}$ TWEAK protein and the amounts of LDH in culture supernatants was measured at $24,48,72$ and $96 \mathrm{~h}$. There was no significant difference in the amounts of LDH in culture supernatants at $24 \mathrm{~h}$ after addition of TWEAK. However, the amounts of LDH were significantly increased in TWEAK-treated cultures compared to controls after $48 \mathrm{~h}$ of treatment. Moreover, the amounts of LDH in culture supernatants was significantly higher in cultures treated with $100 \mathrm{ng} / \mathrm{ml}$ of TWEAK compared to 10 $\mathrm{ng} / \mathrm{ml}$ indicating a dose-dependent effect of TWEAK on myotube viability (Figure 3.1B). These results suggest that TWEAK diminishes the survival of primary myotubes in cultures.

TWEAK induces apoptosis in myotube cultures. Cell death can occur through apoptosis $^{87}$ or necrosis ${ }^{141,142}$. Thusly, we next investigated whether TWEAK induces apoptosis in cultured myotubes. Primary myotubes were treated with 100 $\mathrm{ng} / \mathrm{ml}$ TWEAK for $48 \mathrm{~h}$ and both floating and adherent myotubes were collected. The cells were incubated with propidium iodide $(\mathrm{PI})$ dye, which is membrane impermeant and only binds to DNA once the cell membrane has been compromised. The cells were also incubated with antibody against Annexin $\mathrm{V}, \mathrm{a}$ marker for apoptosis through binding to phosphatidylserine, which is normally localized to the inner leaflet of the plasma membrane. The cells were analyzed by performing FACS. Intriguingly, treatment of cells with TWEAK increased both early and late apoptosis in cultured myotubes (Figure 3.2A). Quantification of 
Annexin $\mathrm{V}^{+}$and $\mathrm{Pl}^{+}$cells further confirmed that TWEAK increased both early and late apoptosis in cultured myotubes (Figure 3.2B).

\section{TWEAK increases the levels of various biochemical markers of apoptosis}

in cultured myotubes. Apoptosis is a highly coordinated process which involves the activation of a number of caspases, ultimately culminating in cell death ${ }^{143}$. Many of the caspases undergo proteolytic cleavage leading to their activation ${ }^{24}$. Using Western blot, we measured the levels of various caspases. As shown in Figure 3, treatment with TWEAK significantly increased the levels of cleaved isoforms of capsase-3 and caspase-9 in myotubes (Figure 3.3).

Poly (ADP-ribose) polymerase (PARP) is an important protein which is involved in DNA repair in response to a variety of environmental stresses. PARP is one of the main cleavage targets of caspase-3 both in vitro and in vivo ${ }^{144}$. Cleavage of PARP facilitates cellular disassembly and serves as a marker of cells undergoing apoptosis ${ }^{145}$. Our immunoblotting analysis showed that TWEAK drastically increases the levels PARP in cultured myotubes within $24 \mathrm{~h}$, further confirming that treatment of TWEAK induces apoptosis of myotubes (Figure 3.3).

Apoptosis-inducing factor (AIF) is a ubiquitously expressed flavoprotein that plays a critical role in the intrinsic apoptotic pathway. AIF is normally localized to the mitochondrial intermembrane space and released in response to apoptotic stimuli88. Moreover, Bax is a key component for apoptosis induced through mitochondrial stress as well. Upon apoptotic stimulation, Bax forms oligomers and translocates from the cytosol to the mitochondrial membrane ${ }^{85}$. 
Through interactions with pore proteins on the mitochondrial membrane, Bax increases the membrane's permeability, which leads to the release of cytochrome c from mitochondria, activation of caspase-9, and initiation of the caspase activation pathway for apoptosis ${ }^{85}$. We measured the levels of AIF and Bax in control and TWEAK-treated myotube cultures by performing western blot (Figure 3.3). Our results showed that TWEAK slightly increases the levels of both AIF and Bax proteins in myotubes. These results indicate that both the intrinsic and extrinsic pathways may be involved in the induction of apoptosis in response to TWEAK.

\section{Z-VAD-FMK, a pan-caspase inhibitor reduces the TWEAK-induced}

cytotoxicity in myotube cultures. We next investigated whether apoptosis is a mechanism of TWEAK-induced cell death. We used z-VAD-FMK, a cell permeable peptide which effectively reduces the activation of various caspases $^{103}$. Myotube cultures were incubated with vehicle alone (i.e. DMSO) or $20 \mu \mathrm{M} z$-VAD-FMK peptide. After $2 \mathrm{~h}$, the cells were treated with 10 or $100 \mathrm{ng} / \mathrm{ml}$ TWEAK for 48 or $72 \mathrm{~h}$. As shown in Figure 3.4A, treatment with z-VAD-FMK peptide considerably improved the survival of myotubes in TWEAK-treated cultures. Moreover, the amounts of LDH in culture supernatants was significantly reduced in TWEAK-treated cultures incubated with z-VAD-FMK (Figure 3.4B). These results suggest that apoptosis contributes to myotube mortality in response to TWEAK. 
TWEAK induces necroptosis in cultured myotubes. Apoptosis has been traditionally considered as the physiological mode of cell death. However, necroptosis, which is morphologically related to necrosis, is now recognized as another mode of programmed cell death ${ }^{141,146}$. RIP1 kinase is activated through oligomerization of upstream adaptor molecules such as FADD and TNF receptorassociated death domain (TRADD) that are triggered by TNFa or Fas ligand ${ }^{147}$. Subsequently, activated RIP1 activates RIP3 resulting in necroptosis. We next investigated whether TWEAK induces the markers of necroptosis in myotubes. As shown in Figure 3.5A, treatment of cells with TWEAK increased the levels of RIP1 and RIP3, although there are some nonspecific bands, in cultured myotubes suggesting that necroptosis may also contribute to cell death in response to TWEAK treatment. Recently, a peptide inhibitor of necroptosis known as necrostatin-1 (Nec-1) was developed which inhibits the activity of RIP1 ${ }^{148}$. To understand whether necroptosis is a mechanism of TWEAK-induced myotube cell death, we employed Nec-1. We found that pretreatment with $\mathrm{Nec}-1$ did not considerably reduce the TWEAK-induced cell death in myotube cultures (Figure 3.5B). Interestingly, the LDH assay showed that pretreatment with $\mathrm{Nec}-1$ significantly reduced the amount of LDH (Figure 3.5C). Further studies are required to elucidate the role of RIP1 in TWEAK-induced cell death. Collectively, these results suggest that TWEAK induces both necroptosis and apoptosis in cultured primary myotubes; however, 
TWEAK induces oxidative stress in cultured myotubes. While TWEAK receptor Fn14 contains TRAF binding domains, it lacks the death receptor domain. Recent studies have suggested that oxidative stress is one of the important stimuli which can lead to cell death through both apoptosis and necroptosis ${ }^{134}$. Previous studies have shown that proinflammatory cytokines such as TNF- $\alpha$ induce oxidative stress in cultured myotubes ${ }^{149,150}$. We next sought to investigate whether TWEAK can induce oxidative stress in myotubes. For measuring oxidative stress, we used the CellROX Deep Red reagent, a cellpermeant, fixable fluorogenic probe of ROS. The CellROX probe reacts with ROS such as: superoxide anion, hydroxyl radical, peroxynitrite, and to a lesser extent, nitric oxide (Invitrogen communication). By competing with endogenous antioxidants, CellROX functions as a marker of excessive ROS and therefore, oxidative stress. Primary myogenic cultures were treated with 10 or $100 \mathrm{ng} / \mathrm{ml}$ of TWEAK for $24 \mathrm{~h}$ after which the cells were incubated with the CellROX probe followed by counterstaining with Hoechst. A fluorescence microscope was used to capture pictures of the myotubes. In the group treated with $10 \mathrm{ng} / \mathrm{ml}$ of TWEAK, there wasn't a significant increase in the levels of oxidative stress. However, the amount of oxidative stress in myotubes was drastically increased upon treatment with $100 \mathrm{ng} / \mathrm{ml}$ of TWEAK (Figure 3.6). These results indicate that TWEAK induces oxidative stress in cultured myotubes.

TWEAK perturbs the expression of various pro-oxidant and antioxidant molecules in cultured myotubes. Redox homeostasis is maintained by a 
delicate balance between the production of potentially cytotoxic ROS and the cellular production of antioxidant molecules ${ }^{119}$. We next investigated whether TWEAK affects the expression of genes whose products are involved in the regulation of redox balance. Primary myotubes were treated with vehicle alone or $100 \mathrm{ng} / \mathrm{ml}$ of TWEAK for $48 \mathrm{~h}$. The cells were analyzed by performing quantitative real-time PCR (QRT-PCR) assay. As shown in Figure 3.7, TWEAK drastically reduced the levels of several antioxidant molecules including SOD2 and SOD3, GPx1 and, CAT in myotubes. By contrast, the mRNA levels of xanthine oxidoreductase $(\mathrm{XDH})$, a pro-oxidant molecule, were significantly upregulated in TWEAK-treated cultures (Figure 3.7). Additionally, the expression of another prooxidant molecule, NOX2, was elevated. These results suggest that TWEAK induces oxidative stress by perturbing the expression of pro-oxidant and antioxidant molecules.

\section{$\mathrm{N}$-acetyl Cysteine (NAC) reduces cell death in TWEAK-treated primary}

myotube cultures. $\mathrm{N}$-acetyl cysteine (NAC), a general antioxidant, has been shown to reduce levels of ROS and carbonylated proteins in skeletal muscle in many disease models ${ }^{151-153}$. We investigated whether NAC can prevent cell death in TWEAK-treated myotube cultures. Primary myotubes were incubated with vehicle alone, 0.1 , or $0.5 \mathrm{mM} \mathrm{NAC}$ for $2 \mathrm{~h}$ followed by treatment with 100 $\mathrm{ng} / \mathrm{ml}$ of TWEAK for $72 \mathrm{~h}$. The amount of LDH produced in culture supernatants was measured using a colorimetric assay. Treatment of myotubes with NAC alone had no effect on the survival of myotubes. Moreover, there was no 
significant difference in the levels of TWEAK-induced cytotoxicity in myotube cultures treated with vehicle alone or $0.1 \mathrm{mM}$ NAC. Interestingly, we found that TWEAK-induced cytotoxicity was significantly reduced in the presence of $0.5 \mathrm{mM}$ NAC (Figure 3.8). These results provide initial evidence that TWEAK may induce myotube mortality through disrupting redox balance.

\section{TWEAK perturbs oxidative stress in skeletal muscle during denervation.}

We have previously reported that TWEAK-Fn14 system is a major mediator of denervation-induced skeletal muscle atrophy ${ }^{67,154}$. We investigated whether TWEAK affects the expression of specific genes which are involved in redox homeostasis. The hind limb muscle of 2 month old wild-type and TWEAK-KO mice were denervated by transection of sciatic nerve and 3 days later, the gastrocnemius muscle was isolated. By performing QRT-PCR assay, we first investigated how the expression of various oxidant and anti-oxidant molecules are affected by denervation. Results showed that the mRNA levels of SOD1, SOD3, GPx1, GPx2, XDH, and NOX2 were increased whereas the levels of SOD2 are reduced in WT denervated muscle compared to corresponding WT undenervated controls (Figure 3.9A). We also compared the mRNA levels of these molecules in undenervated and denervated skeletal muscle of TWEAK-KO mice. Interestingly, we did not observe any increase in the mRNA levels of most of these oxidant and anti-oxidant genes (Figure 3.9B). While statistical significance could not be achieved due to a small number of mice in each group $(\mathrm{N}=3)$, these results provide initial evidence that oxidative stress is increased in 
skeletal muscle upon denervation and TWEAK may be a major player in such induction. We are planning to perform additional experiments where a larger cohort of mice will be used and QRT-PCR analysis will be performed at different time points after denervation. 
A.

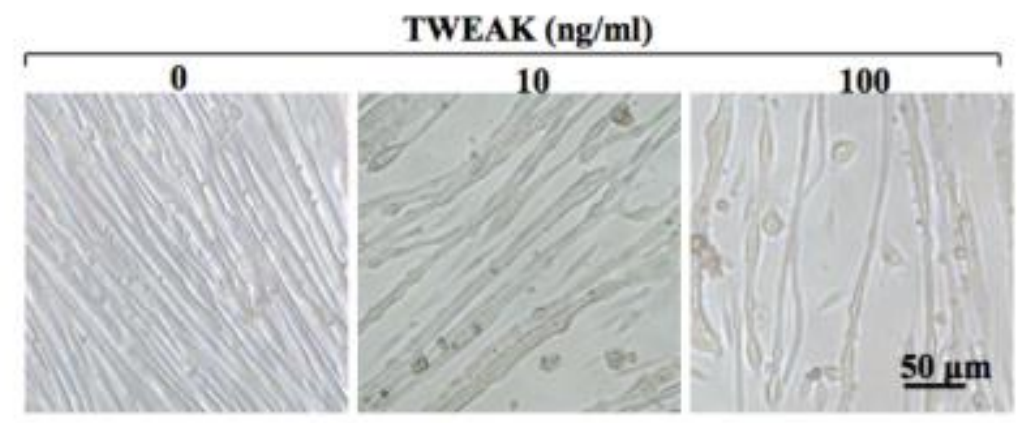

B.

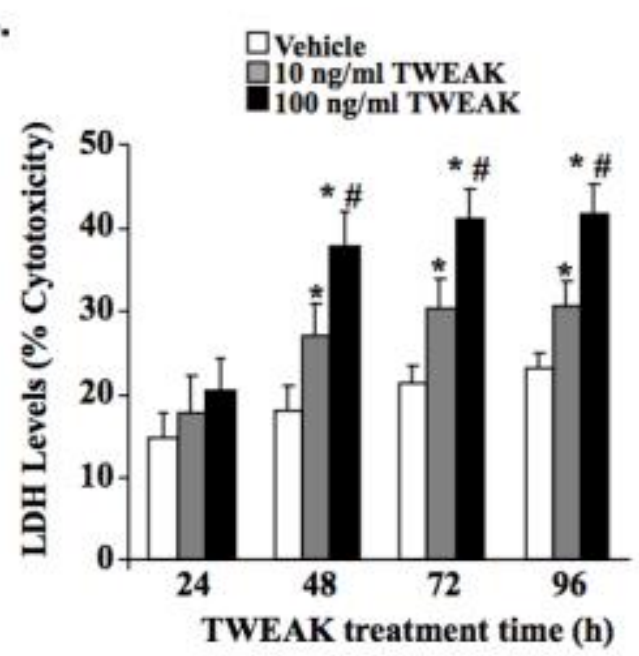

FIGURE 3.1. TWEAK induces cytotoxicity in mouse primary myotube

cultures. (A) Mouse primary myotubes were treated with $10 \mathrm{ng} / \mathrm{ml}$ or $100 \mathrm{ng} / \mathrm{ml}$ of TWEAK for $72 \mathrm{~h}$. Representative images presented here demonstrate that myotube atrophy and cell death were increased in a dose-dependent manner. (B) Mouse primary myotubes were treated with $10 \mathrm{ng} / \mathrm{ml}$ or $100 \mathrm{ng} / \mathrm{ml}$ of TWEAK for a total of $96 \mathrm{~h}$. An LDH assay was performed on cell culture supernatant at each time point. TWEAK causes a progressive dose-dependent increase in cytotoxicity. $\mathrm{N}=3$ at each time point. ${ }^{*} \mathrm{p}<0.05$, values significantly different from vehicle-treated controls at indicated time points. ${ }^{\#} p<0.05$, values significantly different from cultures treated with $10 \mathrm{ng} / \mathrm{ml}$ TWEAK. 
A.

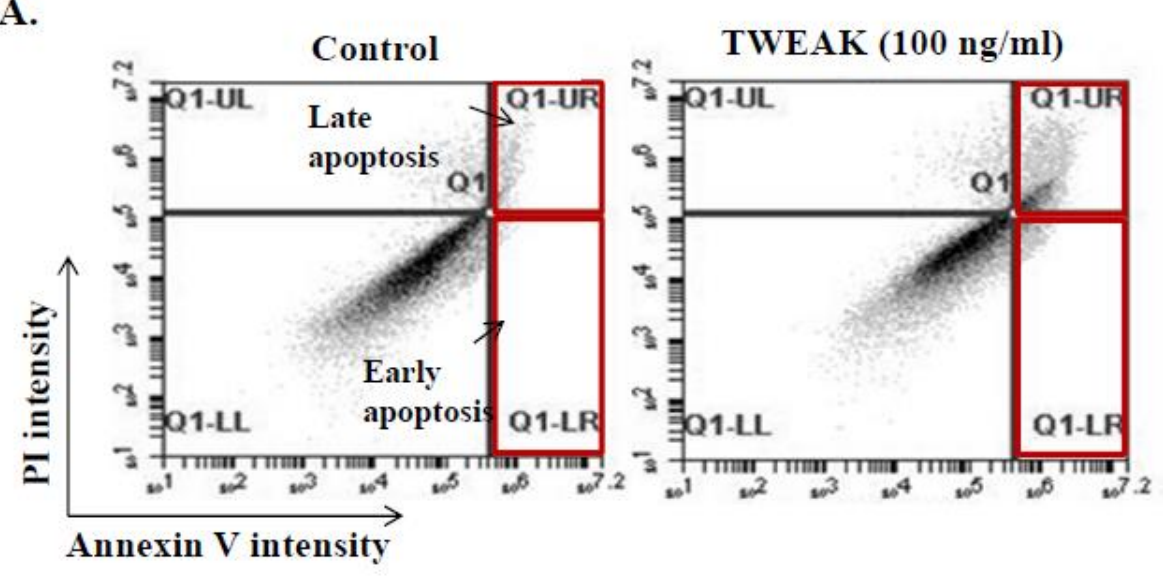

B.

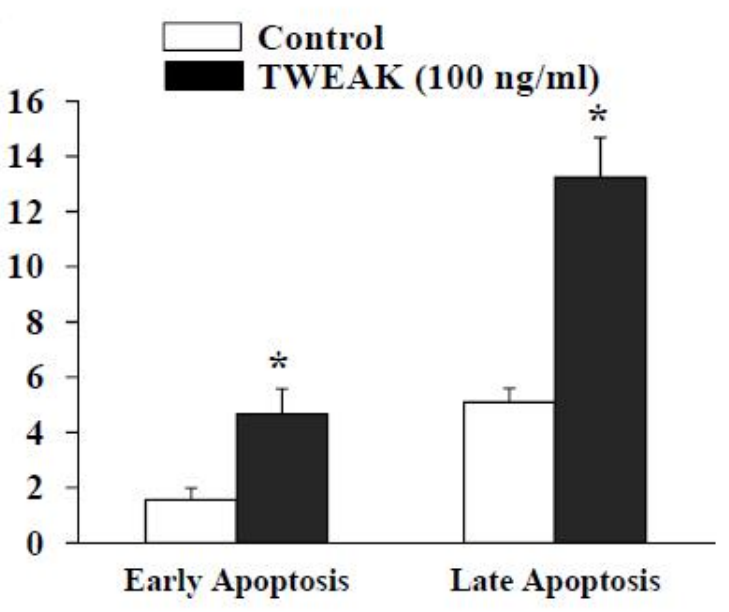

FIGURE 3.2. TWEAK induces apoptosis in myotube cultures. Myotubes were treated with vehicle alone or $100 \mathrm{ng} / \mathrm{ml}$ of soluble TWEAK protein for $48 \mathrm{~h}$. The cells were collected, stained with $\mathrm{PI}$ and Annexin $\mathrm{V}$ and subjected to FACS analysis. (A) Representative dot plots of control and TWEAK-treated mouse primary myotubes. (B) Quantification of early and late apoptosis in control and TWEAK-treated myotube cultures assayed by the FACS method. Results demonstrate that TWEAK increases both early and late apoptosis as characterized by Annexin V vs. PI intensity. $N=3$ in each group. ${ }^{*} \mathrm{p}<0.05$, values significantly different from control cultures. 


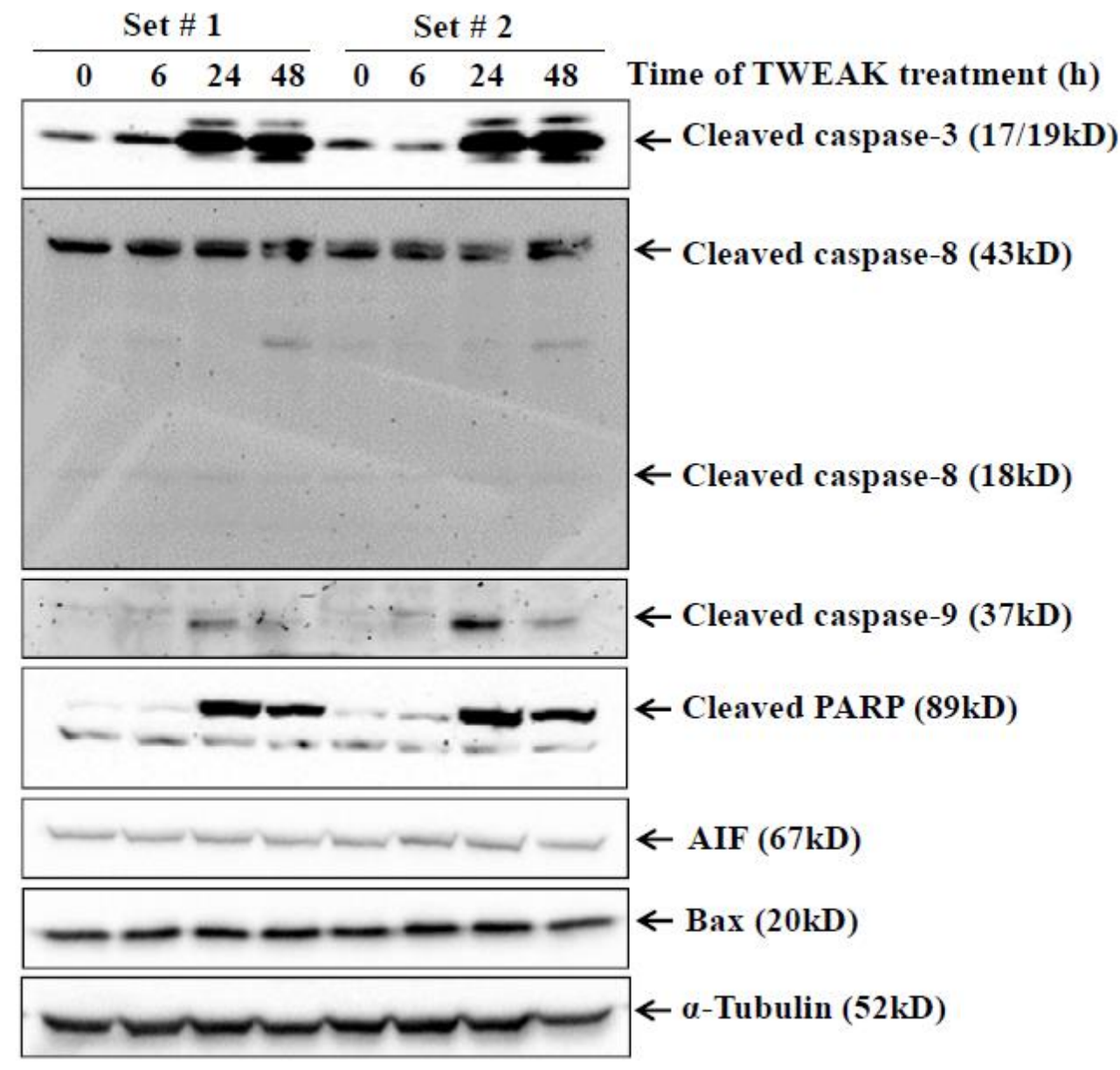

FIGURE 3.3. TWEAK increases the levels of biochemical markers of apoptosis in cultured myotubes. Myotubes were treated with $100 \mathrm{ng} / \mathrm{ml}$ TWEAK protein for different time points ranging from 0 to $48 \mathrm{~h}$. Protein extracts made were analyzed for the levels of various proteins involved in apoptosis. Immunoblots presented from two independent sets of experiments show that TWEAK increases the levels of cleaved PARP, cleaved caspase-3, and -9, AIF, and Bax in cultured myotubes. 
A.

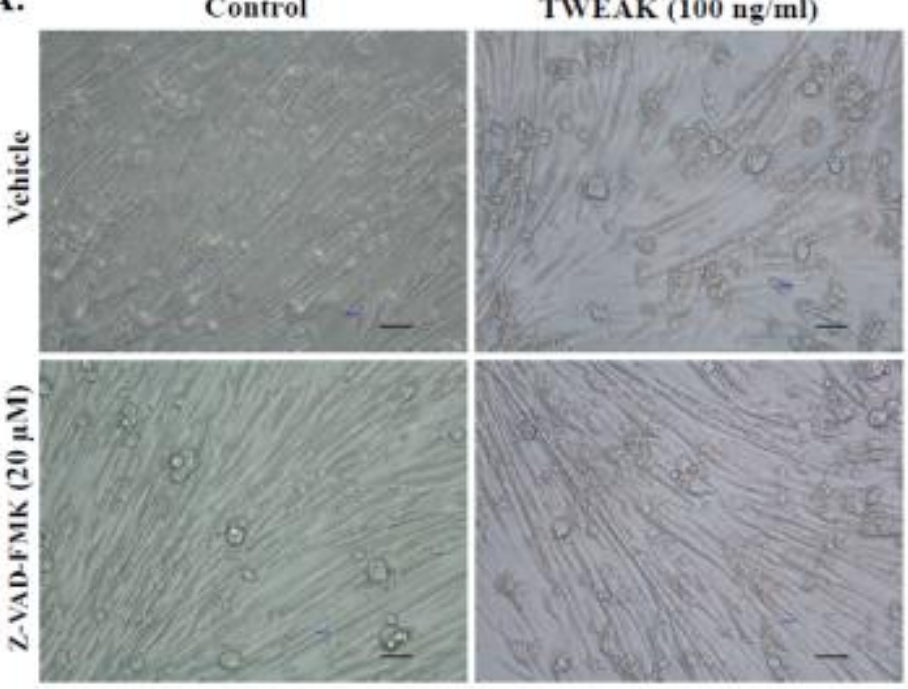

B.

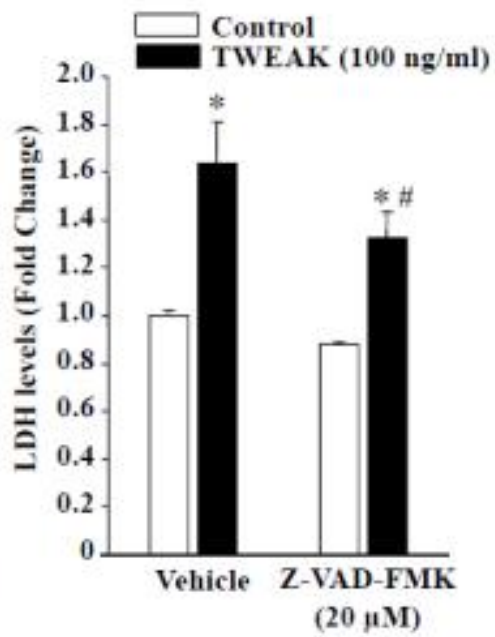

FIGURE 3.4. Inhibition of caspases reduces TWEAK-induced cytotoxicity in myotube cultures. (A) Fully differentiated myotubes were pre-incubated with $20 \mu \mathrm{M}$ Z-VAD-FMK, a pan-caspase inhibitor, for $2 \mathrm{~h}$ followed by treatment with the indicated amount of TWEAK for 48h. Bright-field images were taken and representative images suggest that treatment with Z-VAD-FMK considerably

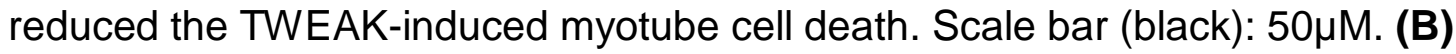
An LDH assay was performed to quantify the cytotoxicity with respect to the pancaspase inhibitor, Z-VAD-FMK. At 72h after TWEAK treatment, there is a drastic increase in cytotoxicity in the groups treated with $100 \mathrm{ng} / \mathrm{ml}$ of TWEAK.

Treatment with Z-VAD-FMK significantly decreased the cytotoxicity in TWEAKtreated myotubes. $\mathrm{N}=3$ in each group. ${ }^{*} \mathrm{p}<0.05$, values significantly different from control cultures. \#p<0.05, values significantly different from TWEAK-treated cultures incubated without Z-VAD-FMK peptide. 
A.

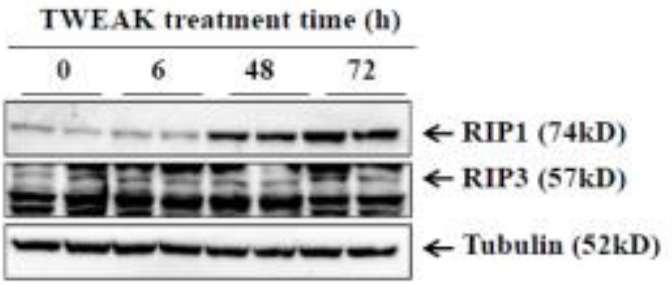

B.

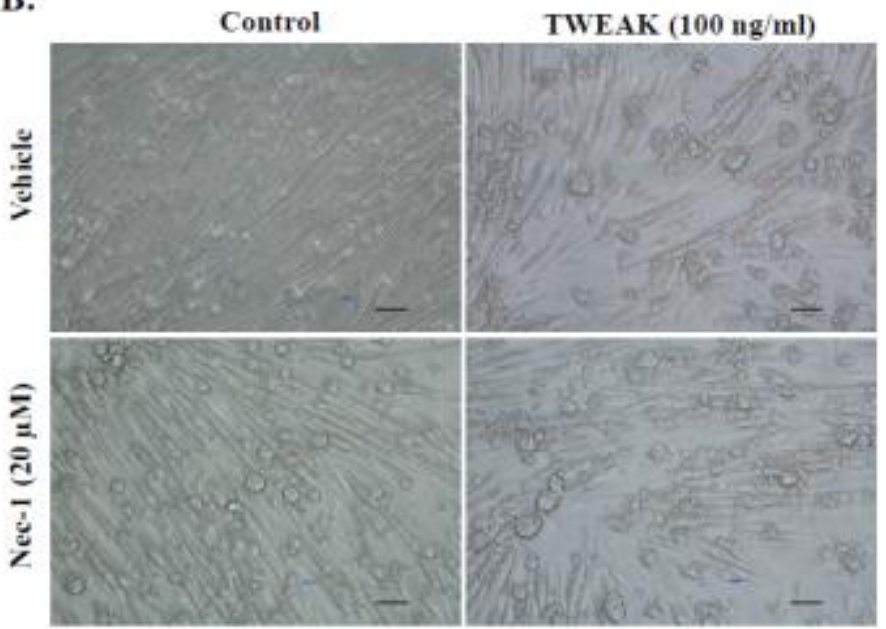

C.

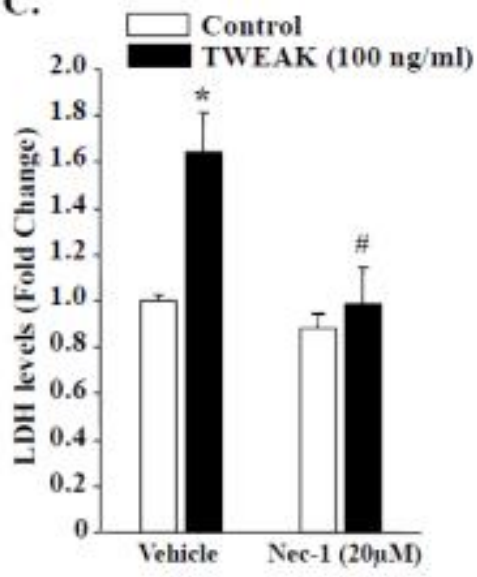

FIGURE 3.5. TWEAK induces necroptosis in cultured myotubes. (A) Primary myotubes were treated with $100 \mathrm{ng} / \mathrm{ml}$ TWEAK protein for indicated time period and the levels of RIP1 and RIP3 protein were assayed by performing western blot. Representative immunoblots presented here demonstrate that TWEAK increases the levels of RIP1 and RIP3 in cultured myotubes. (B) Myotubes were pre-incubated with $20 \mu \mathrm{M} \mathrm{Nec}-1$ for $2 \mathrm{~h}$ followed by treatment with $100 \mathrm{ng} / \mathrm{ml}$ TWEAK for 48h. Representative phase contrast images presented here demonstrate that treatment with $\mathrm{Nec}-1$ considerably reduced TWEAK-induced myotube cell death. Scale bar: $50 \mu \mathrm{M}$. (C) An LDH assay was performed to quantify the cytotoxicity with respect to the RIP1 inhibitor, Nec-1. Interestingly, at $72 \mathrm{~h}$ the Nec-1 treated group displayed a substantial decrease in cytotoxicity relative to TWEAK-treated controls. $\mathrm{N}=3$ in each group. ${ }^{*} p<0.05$, values 
significantly different from control cultures. ${ }^{\#} p<0.05$, values significantly different from TWEAK-treated cultures incubated without Nec-1 peptide. 


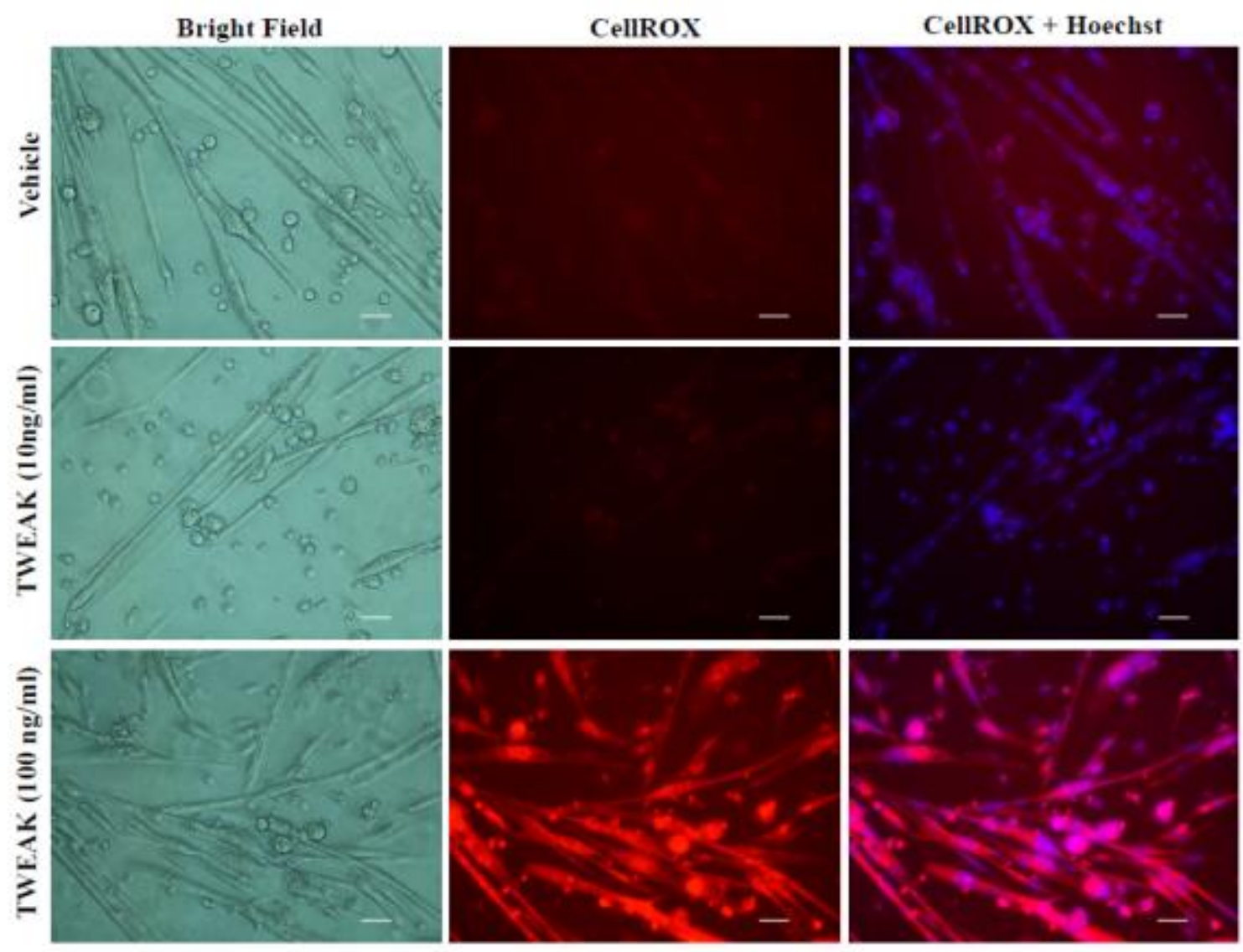

FIGURE 3.6. TWEAK induces oxidative stress in cultured myotubes.

Myotubes were treated with the indicated amounts of TWEAK for $24 \mathrm{~h}$ and stained with the CellROX reagent. The CellROX reagent is non-fluorescent while in a reduced state and subsequently exhibits bright fluorescence when oxidized by ROS. Representative images present here demonstrate that $100 \mathrm{ng} / \mathrm{ml}$ of TWEAK induced significant oxidative stress. Scale: $25 \mu \mathrm{m}$. 


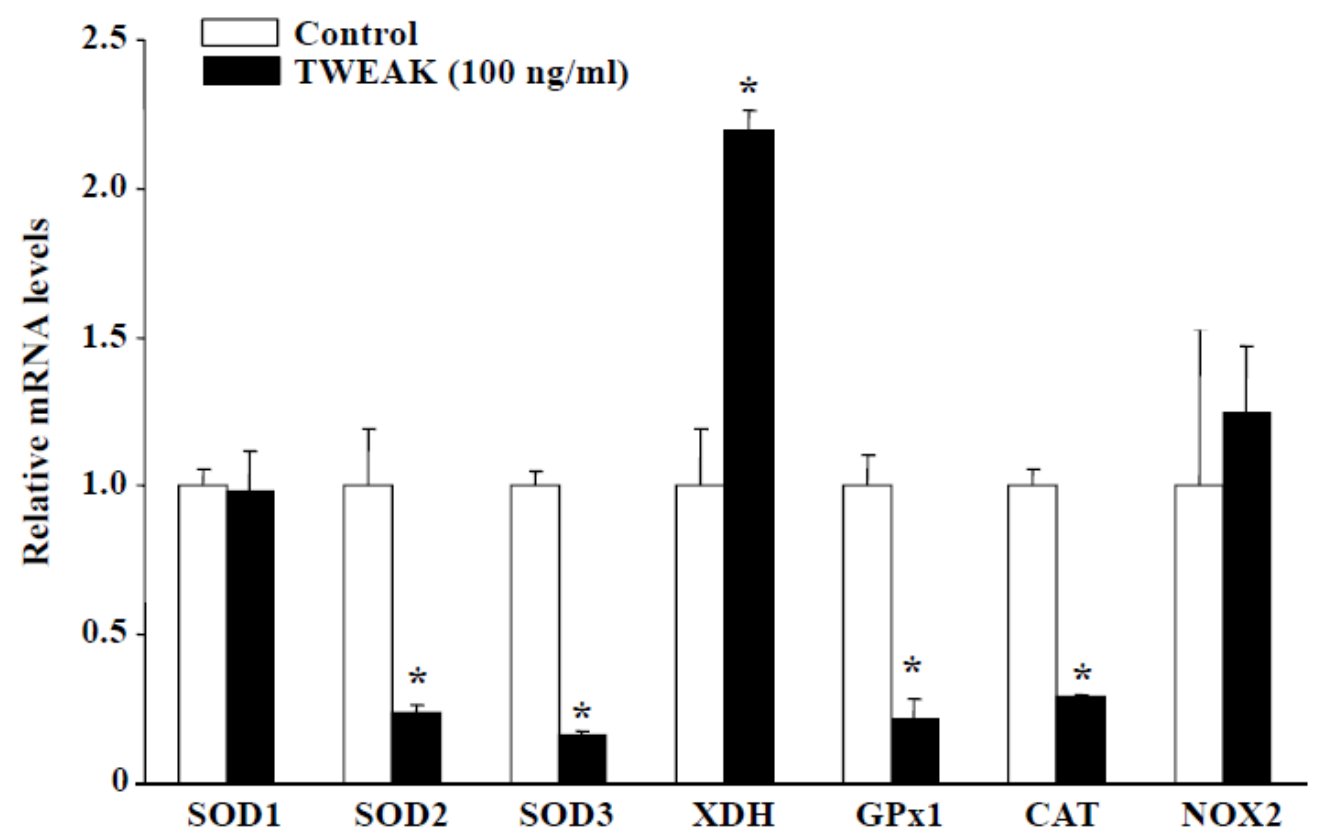

FIGURE 3.7. TWEAK perturbs the expression of various oxidant and antioxidant molecules in cultured myotubes. Myotubes were treated with 100 $\mathrm{ng} / \mathrm{ml}$ of TWEAK for $48 \mathrm{~h}$ and mRNA levels were measured by QRT-PCR. There was a decrease in all of the antioxidant enzymes except SOD1 with a concurrent increase in the oxidant enzymes, XDH and NOX2. These results indicate that TWEAK induces oxidative stress through modulating the levels of various oxidant and anti-oxidant molecules. $\mathrm{N}=3$ in each group. ${ }^{*} \mathrm{p}<0.05$, values significantly different from control cultures. 


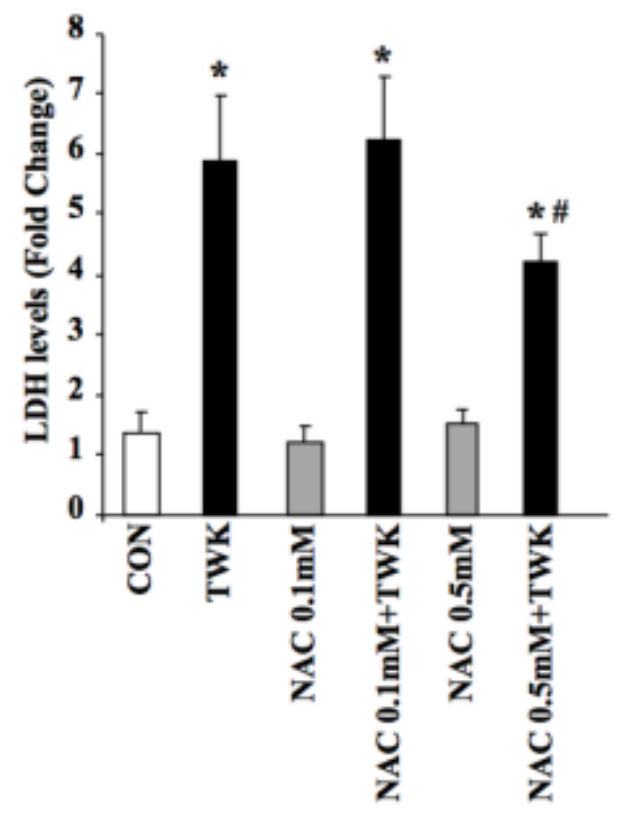

FIGURE 3.8. N-acetyl cysteine (NAC) inhibits TWEAK-induced cell death in myotube cultures. Fully differentiated myotubes were pretreated with the indicated concentrations of NAC for $2 \mathrm{~h}$ and subsequently treated with $100 \mathrm{ng} / \mathrm{ml}$ of TWEAK for $72 \mathrm{~h}$. An LDH assay was performed to quantify the cytotoxicity with respect to NAC. At the lower concentration, NAC did not reduce cytotoxicity relative to the myotubes treated with TWEAK alone. However, the higher concentration of NAC significantly reduced cytotoxicity in TWEAK-treated myotubes, but still remained high relative to untreated myotubes. ${ }^{*} p<0.05$, values significantly different from corresponding cultures incubated without TWEAK. ${ }^{p}<0.05$, values significantly different from TWEAK-treated cultures incubated without or with $0.1 \mathrm{mM} \mathrm{NAC \text {. }}$ 

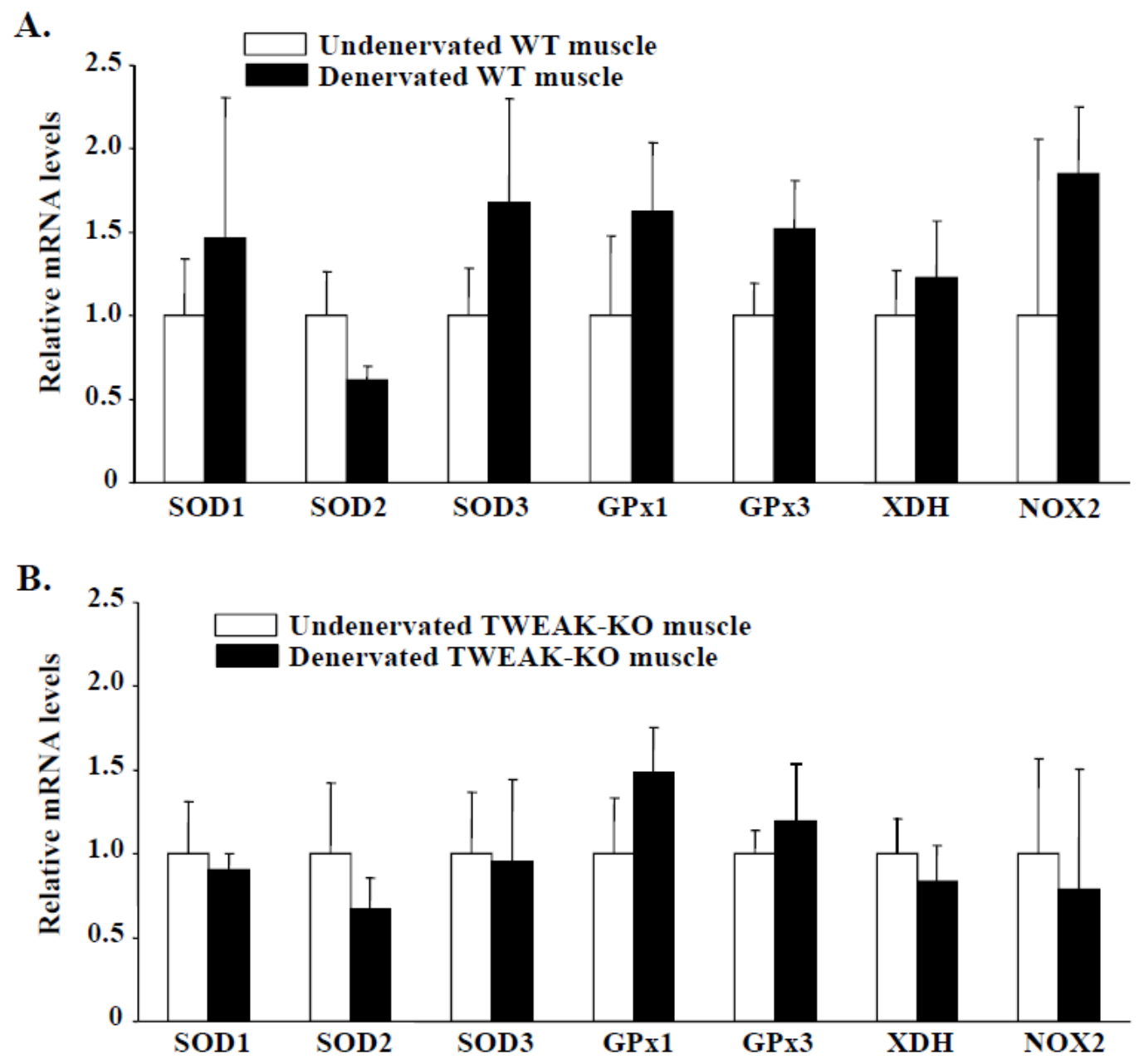

FIGURE 3.9. Absence of TWEAK perturbs the antioxidant and oxidant mRNA expression after denervation. A 2-3 mm section of sciatic nerve was removed from the hind limb of 2 month old wild-type and TWEAK-KO mice. A sham incision was made on the contralateral hind limb and then sutured accordingly. The mice were allowed to recover for three days and then euthanized. The gastrocnemius muscle was isolated and used to measure relative mRNA levels of various oxidant and antioxidant molecules by performing QRT-PCR assay. (A) Relative mRNA levels of SOD1, SOD2, SOD3, GPx1, GPx3, XDH and NOX2 in control and 3d denervated muscle of wild-type mice. 
Results demonstrate that the mRNA levels of all these molecules except SOD2 is increased in denervated muscle compared to contralateral undenervated muscle. (B) Relative mRNA levels of SOD1, SOD2, SOD3, GPx1, GPx3, XDH and NOX2 in control and 3d denervated muscle of TWEAK-KO mice. Interestingly, there was no major change in mRNA levels of all these molecules in denervated muscle of compared to contralateral undenervated muscle of TWEAK-KO mice suggesting that TWEAK is involved in perturbing the expression of various oxidant and antioxidant molecules in skeletal muscle upon denervation. 


\section{CHAPTER 4: CONCLUSIONS AND FUTURE WORK}

This chapter summarizes the work presented in this thesis and discusses its implications in understanding the mechanisms of TWEAK-induced skeletal muscle loss. It also highlights the significance of the findings obtained throughout this thesis while acknowledging the limitations in implementing such findings in future research.

\section{Review of thesis}

Skeletal muscle fibers are syncytia which arise from the fusion of myoblasts during development. Loss of skeletal muscle mass is a devastating consequence of a large number of chronic disease states such as cancer, diabetes, chronic heart failure, chronic obstructive pulmonary disease, AIDS, high-dose glucocorticoid therapy, renal failure, burn injury, and cystic fibrosis. Moreover, prolonged inactivity that occurs during unloading, immobilization, microgravity, bed rest, or nerve injury also results in the loss of skeletal muscle mass.

The TWEAK-Fn14 system has now emerged as a major regulator of skeletal muscle mass. As summarized in Chapter 1, the understanding of the role and mechanisms of activation of TWEAK-Fn14 system in skeletal muscle development, regeneration, atrophy, oxidative metabolism, and regenerative response has taken a quantum leap in recent years. Most of the studies have shown that TWEAK causes deleterious effects leading to an overall deficit in 
skeletal muscle mass and strength. Furthermore, major progress has also been made about the differential signaling potential of the TWEAK-Fn14 axis, increasing appreciation of its complexity. This demands for a more thorough investigation of its effects on skeletal muscle cells, especially in the context of sustained TWEAK/Fn14 signaling so as to better understand its pathogenic roles in settings of chronic muscle injury such as muscular dystrophy and skeletal muscle atrophy in various catabolic conditions. TWEAK or Fn14 null mice are viable and fertile and show no major abnormalities in naïve conditions. For this reason, we believe the TWEAK-Fn14 system is among the most attractive drug targets for the prevention of muscle loss. Since TWEAK is an extracellular protein, TWEAK-dependent signaling can be blocked using a TWEAK neutralizing antibody or soluble Fn14-Fc decoy protein, which can prevent TWEAK binding to Fn14 receptors on cells.

To understand the mechanisms of action of TWEAK on skeletal muscle, I focused my thesis on the cell survival aspect and oxidative stress. We have found that TWEAK induces myotube cell death. The physiological significance of TWEAK-induced muscle cell death is currently unknown. However, it is possible that elevated levels of TWEAK contribute to muscle death especially in conditions such as muscular dystrophy where the sarcolemma is already weak and the inflammatory immune response is exacerbated. Moreover, TWEAK may induce selective myonuclear apoptosis in myofibers leading to a reduced myonuclear domain and a reduction in the size of the myofiber. Apoptosis has been shown to play a role in skeletal muscle wasting in many conditions 
including denervation, aging, and some forms of muscular dystrophy. The results presented in this thesis suggest that TWEAK can induce apoptosis in cultured myotubes. Our results also suggest that both mitochondrial-dependent and independent apoptotic pathways can be induced in myotubes upon treatment with TWEAK. We have previously reported that TWEAK induces the activation of various caspases in cultured myotubes which may contribute to muscle proteolysis in various conditions ${ }^{75}$. Expanding on those studies, our results in the present study suggest that TWEAK-induced activation of caspases can also lead to myotube death. Our results have demonstrated that TWEAK-induced muscle cell death is partially inhibited in the presence of a pan-caspase inhibitor.

In recent years, necroptosis has emerged as another form of programmed cell death. Although there have not been many studies about the involvement of necroptosis in skeletal muscle so far, it may be an important mechanism of muscle cell death in various muscle degenerative disorders. While more investigations are needed, our study provides initial evidence that the TWEAKFn14 system can induce necroptosis in myotubes. Indeed, we found that necrostatin-1 inhibits TWEAK-induced cytotoxicity. Together, our findings provide initial evidence that inhibition of TWEAK-Fn14 signaling can improve skeletal muscle survival.

Oxidative stress is a major player in both the physiology and the pathophysiology of skeletal muscle. Previous studies have shown that proinflammatory cytokines induce the production of ROS in skeletal muscle through distinct mechanisms. Oxidative stress, by itself, can be a stimulus for the 
activation of various proteolytic systems in skeletal muscle. Furthermore, oxidative stress can produce irreversible changes in various cell types leading to cell death. Our experiments have provided initial evidence that TWEAK induces oxidative stress, which in part contributes to myotube death. Although the exact mechanisms remain unknown, our experiments also suggest that TWEAK affects the expression of various oxidant and antioxidant genes in skeletal muscle.

Future studies will determine how TWEAK is responsible for the development of oxidative stress in atrophying skeletal muscle.

\section{Contribution of thesis and future implementations}

The work presented in this thesis provides additional mechanisms for TWEAKinduced skeletal muscle loss. These studies have wider application for skeletal muscle disorders because TWEAK-Fn14 axis has been implicated not only in skeletal muscle atrophy, but in the pathogenesis of many degenerative muscle disorders as well. Additional studies will need to be conducted to dig deeper into how TWEAK-Fn14, oxidative stress, and downstream effector pathways are connected and modulated in a context-specific manner. A few ideas for future implementations are mentioned below.

Mechanistic studies need to be performed to show how TWEAK-Fn14 signals via an alternative extrinsic pathway leading to apoptosis and/or necroptosis. Since the Fn14 receptor lacks a DD, yet contains a TRAF-binding domain, it remains unknown exactly how TWEAK signals these pathways. It would be interesting to see which molecules interact with specific TRAFs and 
complex to initiate pro-apoptotic or pro-necroptotic pathways. This could be done with the use of genetic and immunological techniques to further support the data that we have shown here.

Additional studies on TWEAK and oxidative stress also need to be conducted in cultured myotubes to determine the specific role that oxidative stress plays in TWEAK-induced signaling. Monitoring ROS production and relative mRNA levels of antioxidant vs. pro-oxidant levels at additional time points from the start of TWEAK treatment to the late stages of TWEAK-induced myotube atrophy may prove lucrative. Additionally, the use of pharmacological antioxidant mimetics or pro-oxidant inhibitors may provide more insight into the role of oxidative stress in response to TWEAK. These experiments could be repeated using genetic approaches to knockout or upregulate some of the important molecules and observe the impact on TWEAK-treated myotubes as well.

Finally, applying the knowledge that we have gained from the in vitro studies to in vivo models would provide further evidence for the role of oxidative stress, apoptosis, and necroptosis with respect to TWEAK. Utilizing not only TWEAK-KO mice, but also muscle-specific TWEAK-TG mice would provide much more data to hone our findings and draw further conclusions. In addition to the sciatic denervation model that was utilized in this study, it would be interesting to use other models such as skeletal muscle injury, starvation, and muscle disease models (Duchenne muscular dystrophy and Mdx mouse) to see 
if there are context-dependent alterations in TWEAK's modulation of these processes.

\section{Limitations of future implementations}

The thesis concludes that TWEAK is a potent inducer of oxidative stress in skeletal muscle cells. In TWEAK's initial characterization it was described as a protein that did not induce apoptosis through the canonical death domain and it was suggested that TWEAK signals apoptosis via an alternative entry point into the caspase-mediated death cascade and was therefore coined as a "weak" inducer of apoptosis ${ }^{42}$. This idea was further compounded by the initial characterization of the Fn14 receptor in that it did not have the death domain (DD) characteristic of many of the other TNFRSF members. Overall, this lead to the thought that TWEAK had a more prominent role in growth and proliferation. However, our studies suggest that TWEAK can induce apoptosis and necroptosis as well, at least in cultured skeletal muscle cells with the possibility that oxidative stress serves as the mechanistic switch between a pro-survival and a cell deathinducing role.

Initially, ROS were thought to be mediators of disease and high hopes were placed on treating these diseases with high doses of exogenous antioxidants. With mixed results, research in the years since has shown the importance of ROS and redox signaling in normal physiology, possibly providing a reason for the lack of positive results from these studies in various disease models. The disruption to normal signaling could outweigh the perceived benefit 
of exogenous antioxidant supplementation. Targeting endogenous antioxidant regulatory molecules through the use of pro-oxidants may prove more beneficial than exogenous antioxidant supplementation by priming the cell's inherent defense pathways.

Currently, the methods for measuring oxidative stress rely on utilizing fluorogenic reagents, measuring the ratio of reduced to oxidized molecules such as glutathione, or measuring oxidative damage by looking at protein, lipid, and DNA biomarkers to draw conclusions. One current problem is that these fluorogenic probes are unable to distinguish between the different ROS, which limits our ability to draw specific conclusions ${ }^{115}$. For example, being able to determine the role of hydrogen peroxide versus peroxynitrate and being able to see their subcellular localization would allow for a more thorough understanding and allow researchers to pinpoint better therapeutic targets to treat disease. With additional research efforts focused on understanding ROS and redox signaling, more precise methodology and technology will ensue to allow us to study these molecules and their effects in real-time. 


\section{REFERENCES}

1 Bonaldo, P. \& Sandri, M. Cellular and molecular mechanisms of muscle atrophy. Dis Model Mech 6, 25-39, doi:10.1242/dmm.010389 (2013).

2 Jackman, R. W. \& Kandarian, S. C. The molecular basis of skeletal muscle atrophy. American journal of physiology. Cell physiology 287, C834-843, doi:10.1152/ajpcell.00579.2003 (2004).

3 Cohen, S., Nathan, J. A. \& Goldberg, A. L. Muscle wasting in disease: molecular mechanisms and promising therapies. Nat Rev Drug Discov 14, 58-74, doi:10.1038/nrd4467 (2015).

4 Bentzinger, C. F., Wang, Y. X. \& Rudnicki, M. A. Building muscle: molecular regulation of myogenesis. Cold Spring Harb Perspect Biol 4, doi:10.1101/cshperspect.a008342 (2012).

5 Relaix, F. \& Zammit, P. S. Satellite cells are essential for skeletal muscle regeneration: the cell on the edge returns centre stage. Development 139, 2845-2856, doi:10.1242/dev.069088 (2012).

6 Buckingham, M. et al. The formation of skeletal muscle: from somite to limb. J Anat 202, 59-68 (2003).

7 Mauro, A. Satellite cell of skeletal muscle fibers. J Biophys Biochem Cytol 9, 493-495 (1961).

8 Yin, H., Price, F. \& Rudnicki, M. A. Satellite cells and the muscle stem cell niche. Physiological reviews 93, 23-67, doi:10.1152/physrev.00043.2011 (2013).

9 Kuang, S. \& Rudnicki, M. A. The emerging biology of satellite cells and their therapeutic potential. Trends in molecular medicine 14, 82-91, doi:10.1016/j.molmed.2007.12.004 (2008).

10 Tajrishi, M. M., Zheng, T. S., Burkly, L. C. \& Kumar, A. The TWEAK-Fn14 pathway: A potent regulator of skeletal muscle biology in 
health and disease. Cytokine \& growth factor reviews 25, 215-225, doi:http://dx.doi.org/10.1016/i.cytogfr.2013.12.004 (2014).

11 Glass, D. J. Skeletal muscle hypertrophy and atrophy signaling pathways. Int J Biochem Cell Bio/ 37, 1974-1984, doi:S1357-2725(05)00131-7 [pii]

10.1016/j.biocel.2005.04.018 (2005).

12 Hindi, S. M., Tajrishi, M. M. \& Kumar, A. Signaling mechanisms in mammalian myoblast fusion. Science signaling 6, re2, doi:10.1126/scisignal.2003832 (2013).

13 Sandri, M. Signaling in muscle atrophy and hypertrophy. Physiology (Bethesda) 23, 160-170, doi:10.1152/physiol.00041.2007 (2008).

14 Bodine, S. C. et al. Akt/mTOR pathway is a crucial regulator of skeletal muscle hypertrophy and can prevent muscle atrophy in vivo. Nat Cell Biol 3, 1014-1019, doi:10.1038/ncb1101-1014 (2001).

15 Rommel, C. et al. Mediation of IGF-1-induced skeletal myotube hypertrophy by $\mathrm{PI}(3) \mathrm{K} / \mathrm{Akt} / \mathrm{mTOR}$ and $\mathrm{PI}(3) \mathrm{K} / \mathrm{Akt} / \mathrm{GSK} 3$ pathways. Nat Cell Biol 3, 1009-1013, doi:10.1038/ncb1101-1009 (2001).

16 Latres, E. et al. Insulin-like growth factor-1 (IGF-1) inversely regulates atrophy-induced genes via the phosphatidylinositol 3kinase/Akt/mammalian target of rapamycin (PI3K/Akt/mTOR) pathway. $J$ Biol Chem 280, 2737-2744, doi:10.1074/jbc.M407517200 (2005).

17 Sandri, M. et al. Foxo transcription factors induce the atrophy-related ubiquitin ligase atrogin-1 and cause skeletal muscle atrophy. Cell 117, 399-412 (2004).

18 Egerman, M. A. \& Glass, D. J. Signaling pathways controlling skeletal muscle mass. Crit Rev Biochem Mol Biol 49, 59-68, doi:10.3109/10409238.2013.857291 (2014).

19 Frank, N. Y. et al. Regulation of myogenic progenitor proliferation in human fetal skeletal muscle by BMP4 and its antagonist Gremlin. J Cell Biol 175, 99-110, doi:10.1083/jcb.200511036 (2006).

20 Sartori, R. et al. BMP signaling controls muscle mass. Nat Genet 45, 1309-1318, doi:10.1038/ng.2772 (2013).

21 Winbanks, C. E. et al. The bone morphogenetic protein axis is a positive regulator of skeletal muscle mass. J Cell Biol 203, 345-357, doi:10.1083/jcb.201211134 (2013). 
22 Sartori, R., Gregorevic, P. \& Sandri, M. TGFbeta and BMP signaling in skeletal muscle: potential significance for muscle-related disease. Trends Endocrinol Metab 25, 464-471, doi:10.1016/j.tem.2014.06.002 (2014).

23 Sartori, R. \& Sandri, M. Bone and morphogenetic protein signalling and muscle mass. Curr Opin Clin Nutr Metab Care 18, 215-220, doi:10.1097/MCO.0000000000000172 (2015).

24 Du, J. et al. Activation of caspase-3 is an initial step triggering accelerated muscle proteolysis in catabolic conditions. The Journal of clinical investigation 113, 115-123, doi:10.1172/jci18330 (2004).

25 Cohen, S. et al. During muscle atrophy, thick, but not thin, filament components are degraded by MuRF1-dependent ubiquitylation. J Cell Biol 185, 1083-1095, doi:jcb.200901052 [pii] 10.1083/jcb.200901052 (2009).

26 Gomes, M. D., Lecker, S. H., Jagoe, R. T., Navon, A. \& Goldberg, A. L. Atrogin-1, a muscle-specific F-box protein highly expressed during muscle atrophy. Proc Natl Acad Sci U S A 98, 14440-14445, doi:10.1073/pnas.251541198 (2001).

27 Bodine, S. C. et al. Identification of ubiquitin ligases required for skeletal muscle atrophy. Science 294, 1704-1708, doi:10.1126/science.1065874 (2001).

28 Carnio, S. et al. Autophagy impairment in muscle induces neuromuscular junction degeneration and precocious aging. Cell Rep 8, 1509-1521, doi:10.1016/j.celrep.2014.07.061 (2014).

29 Masiero, E. et al. Autophagy is required to maintain muscle mass. Cell Metab 10, 507-515, doi:10.1016/j.cmet.2009.10.008 (2009).

30 Masiero, E. \& Sandri, M. Autophagy inhibition induces atrophy and myopathy in adult skeletal muscles. Autophagy 6, 307-309 (2010).

31 Li, H., Malhotra, S. \& Kumar, A. Nuclear factor-kappa B signaling in skeletal muscle atrophy. $J$ Mol Med (Berl) 86, 1113-1126, doi:10.1007/s00109-008-0373-8 (2008).

32 Sandri, M. Protein breakdown in muscle wasting: role of autophagylysosome and ubiquitin-proteasome. Int J Biochem Cell Biol 45, 21212129, doi:10.1016/j.biocel.2013.04.023 (2013).

33 Bongers, K. S. et al. Skeletal muscle denervation causes skeletal muscle atrophy through a pathway that involves both Gadd45a and HDAC4. Am J Physiol Endocrinol Metab 305, E907-915, doi:10.1152/ajpendo.00380.2013 (2013). 
34 Ebert, S. M. et al. Stress-induced skeletal muscle Gadd45a expression reprograms myonuclei and causes muscle atrophy. J Biol Chem 287, 27290-27301, doi:10.1074/jbc.M112.374777 (2012).

35 Moresi, V. et al. Myogenin and class II HDACs control neurogenic muscle atrophy by inducing E3 ubiquitin ligases. Cell 143, 35-45, doi:10.1016/j.cell.2010.09.004 (2010).

36 Shintaku, J. \& Guttridge, D. C. Reining in nuclear factor-kappaB in skeletal muscle disorders. Curr Opin Clin Nutr Metab Care 16, 251-257, doi:10.1097/MCO.0b013e3283600e79 (2013).

37 Romanello, V. et al. Mitochondrial fission and remodelling contributes to muscle atrophy. EMBO J 29, 1774-1785, doi:10.1038/emboj.2010.60 (2010).

38 Lokireddy, S. et al. The ubiquitin ligase Mul1 induces mitophagy in skeletal muscle in response to muscle-wasting stimuli. Cell Metab 16, 613-624, doi:10.1016/j.cmet.2012.10.005 (2012).

39 Aggarwal, B. B. Signalling pathways of the TNF superfamily: a doubleedged sword. Nature reviews. Immunology 3, 745-756, doi:10.1038/nri1184 (2003).

40 Locksley, R. M., Killeen, N. \& Lenardo, M. J. The TNF and TNF receptor superfamilies: integrating mammalian biology. Cell 104, 487-501 (2001).

41 Aggarwal, B. B., Shishodia, S., Ashikawa, K. \& Bharti, A. C. The role of TNF and its family members in inflammation and cancer: lessons from gene deletion. Current drug targets. Inflammation and allergy 1, 327-341 (2002).

42 Chicheportiche, Y. et al. TWEAK, a new secreted ligand in the tumor necrosis factor family that weakly induces apoptosis. The Journal of biological chemistry 272, 32401-32410 (1997).

43 Wiley, S. R. \& Winkles, J. A. TWEAK, a member of the TNF superfamily, is a multifunctional cytokine that binds the TweakR/Fn14 receptor.

Cytokine \& growth factor reviews 14, 241-249, doi:http://dx.doi.org/10.1016/S1359-6101(03)00019-4 (2003).

44 Wiley, S. R. et al. A Novel TNF Receptor Family Member Binds TWEAK and Is Implicated in Angiogenesis. Immunity 15, 837-846, doi:http://dx.doi.org/10.1016/S1074-7613(01)00232-1 (2001).

45 Meighan-Mantha, R. L. et al. The mitogen-inducible Fn14 gene encodes a type I transmembrane protein that modulates fibroblast adhesion and migration. The Journal of biological chemistry 274, 33166-33176 (1999). 
46 Wajant, H., Grell, M. \& Scheurich, P. TNF receptor associated factors in cytokine signaling. Cytokine \& growth factor reviews 10, 15-26, doi:http://dx.doi.org/10.1016/S1359-6101(98)00023-9 (1999).

47 Inoue, J.-i. et al. Tumor Necrosis Factor Receptor-Associated Factor (TRAF) Family: Adapter Proteins That Mediate Cytokine Signaling. Experimental Cell Research 254, 14-24, doi:http://dx.doi.org/10.1006/excr.1999.4733 (2000).

48 Brown, S. A., Richards, C. M., Hanscom, H. N., Feng, S. L. \& Winkles, J. A. The Fn14 cytoplasmic tail binds tumour-necrosis-factor-receptorassociated factors 1, 2, 3 and 5 and mediates nuclear factor-kappaB activation. The Biochemical journal 371, 395-403, doi:10.1042/bj20021730 (2003).

49 Winkles, J. A. The TWEAK-Fn14 cytokine-receptor axis: discovery, biology and therapeutic targeting. Nature reviews. Drug discovery 7, 411425, doi:10.1038/nrd2488 (2008).

50 Dogra, C., Hall, S. L., Wedhas, N., Linkhart, T. A. \& Kumar, A. Fibroblast growth factor inducible 14 (Fn14) is required for the expression of myogenic regulatory factors and differentiation of myoblasts into myotubes. Evidence for TWEAK-independent functions of Fn14 during myogenesis. The Journal of biological chemistry 282, 15000-15010, doi:10.1074/jbc.M608668200 (2007).

51 Girgenrath, M. et al. TWEAK, via its receptor Fn14, is a novel regulator of mesenchymal progenitor cells and skeletal muscle regeneration. The EMBO journal 25, 5826-5839, doi:10.1038/sj.emboj.7601441 (2006).

52 Dogra, C., Changotra, H., Mohan, S. \& Kumar, A. Tumor necrosis factorlike weak inducer of apoptosis inhibits skeletal myogenesis through sustained activation of nuclear factor-kappaB and degradation of MyoD protein. The Journal of biological chemistry 281, 10327-10336, doi:10.1074/jbc.M511131200 (2006).

53 Enwere, E. K. et al. TWEAK and cIAP1 regulate myoblast fusion through the noncanonical NF-kappaB signaling pathway. Science signaling $\mathbf{5}$, ra75, doi:10.1126/scisignal.2003086 (2012).

54 Ogura, Y., Mishra, V., Hindi, S. M., Kuang, S. \& Kumar, A. Proinflammatory cytokine tumor necrosis factor (TNF)-like weak inducer of apoptosis (TWEAK) suppresses satellite cell self-renewal through inversely modulating Notch and NF-kappaB signaling pathways. The Journal of biological chemistry 288, 35159-35169, doi:10.1074/jbc.M113.517300 (2013). 
55 Bhatnagar, S. \& Kumar, A. The TWEAK-Fn14 system: breaking the silence of cytokine-induced skeletal muscle wasting. Current molecular medicine 12, 3-13 (2012).

56 Shin, J., Tajrishi, M. M., Ogura, Y. \& Kumar, A. Wasting mechanisms in muscular dystrophy. The international journal of biochemistry \& cell biology 45, 2266-2279, doi:10.1016/j.biocel.2013.05.001 (2013).

57 Mittal, A. et al. Genetic ablation of TWEAK augments regeneration and post-injury growth of skeletal muscle in mice. The American journal of pathology 177, 1732-1742, doi:10.2353/ajpath.2010.100335 (2010).

58 Tidball, J. G. \& Villalta, S. A. Regulatory interactions between muscle and the immune system during muscle regeneration. American journal of physiology. Regulatory, integrative and comparative physiology 298, R1173-1187, doi:10.1152/ajpregu.00735.2009 (2010).

59 Schiaffino, S. \& Reggiani, C. Fiber types in mammalian skeletal muscles. Physiological reviews 91, 1447-1531, doi:10.1152/physrev.00031.2010 (2011).

60 Termin, A., Staron, R. S. \& Pette, D. Myosin heavy chain isoforms in histochemically defined fiber types of rat muscle. Histochemistry 92, 453457 (1989).

61 Ennion, S., Sant'ana Pereira, J., Sargeant, A. J., Young, A. \& Goldspink, G. Characterization of human skeletal muscle fibres according to the myosin heavy chains they express. Journal of muscle research and cell motility 16, 35-43 (1995).

62 Pette, D. The adaptive potential of skeletal muscle fibers. Canadian journal of applied physiology = Revue canadienne de physiologie appliquee 27, 423-448 (2002).

63 Arany, Z. PGC-1 coactivators and skeletal muscle adaptations in health and disease. Current opinion in genetics \& development 18, 426-434, doi:10.1016/j.gde.2008.07.018 (2008).

64 Uldry, M. et al. Complementary action of the PGC-1 coactivators in mitochondrial biogenesis and brown fat differentiation. Cell metabolism 3 , 333-341, doi:10.1016/j.cmet.2006.04.002 (2006).

65 Lin, J. et al. Transcriptional co-activator PGC-1 alpha drives the formation of slow-twitch muscle fibres. Nature 418, 797-801, doi:10.1038/nature00904 (2002). 
66 Sato, S. et al. TWEAK promotes exercise intolerance by decreasing skeletal muscle oxidative phosphorylation capacity. Skeletal muscle 3, 18, doi:10.1186/2044-5040-3-18 (2013).

67 Mittal, A. et al. The TWEAK-Fn14 system is a critical regulator of denervation-induced skeletal muscle atrophy in mice. The Journal of cell biology 188, 833-849, doi:10.1083/jcb.200909117 (2010).

68 Shi, J. et al. PGC1alpha plays a critical role in TWEAK-induced cardiac dysfunction. PloS one 8, e54054, doi:10.1371/journal.pone.0054054 (2013).

69 Sato, S., Ogura, Y., Tajrishi, M. M. \& Kumar, A. Elevated levels of TWEAK in skeletal muscle promote visceral obesity, insulin resistance, and metabolic dysfunction. FASEB journal : official publication of the Federation of American Societies for Experimental Biology 29, 988-1002, doi:10.1096/fj.14-260703 (2015).

70 Glass, D. J. Signaling pathways perturbing muscle mass. Current opinion in clinical nutrition and metabolic care 13, 225-229 (2010).

71 Dogra, C. et al. TNF-related weak inducer of apoptosis (TWEAK) is a potent skeletal muscle-wasting cytokine. FASEB journal : official publication of the Federation of American Societies for Experimental Biology 21, 1857-1869, doi:10.1096/fj.06-7537com (2007).

$72 \mathrm{Li}, \mathrm{H}$., Malhotra, S. \& Kumar, A. Nuclear factor-kappa B signaling in skeletal muscle atrophy. Journal of Molecular Medicine 86, 1113-1126, doi:10.1007/s00109-008-0373-8 (2008).

73 Mourkioti, F. et al. Targeted ablation of IKK2 improves skeletal muscle strength, maintains mass, and promotes regeneration. The Journal of clinical investigation 116, 2945-2954, doi:10.1172/jci28721 (2006).

74 Cai, D. et al. IKKbeta/NF-kappaB activation causes severe muscle wasting in mice. Cell 119, 285-298, doi:10.1016/j.cell.2004.09.027 (2004).

75 Bhatnagar, S., Mittal, A., Gupta, S. K. \& Kumar, A. TWEAK causes myotube atrophy through coordinated activation of ubiquitin-proteasome system, autophagy, and caspases. Journal of cellular physiology 227, 1042-1051, doi:10.1002/jcp.22821 (2012).

76 Levine, B. \& Kroemer, G. Autophagy in the pathogenesis of disease. Cell 132, 27-42, doi:10.1016/j.cell.2007.12.018 (2008).

77 Mizushima, N., Levine, B., Cuervo, A. M. \& Klionsky, D. J. Autophagy fights disease through cellular self-digestion. Nature 451, 1069-1075, doi:10.1038/nature06639 (2008). 
78 Zhao, J. et al. FoxO3 coordinately activates protein degradation by the autophagic/lysosomal and proteasomal pathways in atrophying muscle cells. Cell Metab 6, 472-483, doi:10.1016/j.cmet.2007.11.004 (2007).

79 Plant, P. J., Bain, J. R., Correa, J. E., Woo, M. \& Batt, J. Absence of caspase-3 protects against denervation-induced skeletal muscle atrophy. Journal of applied physiology (Bethesda, Md. : 1985) 107, 224-234, doi:10.1152/japplphysiol.90932.2008 (2009).

80 Paul, P. K. et al. The E3 ubiquitin ligase TRAF6 intercedes in starvationinduced skeletal muscle atrophy through multiple mechanisms. Mol Cell Bio/ 32, 1248-1259, doi:10.1128/MCB.06351-11 (2012).

81 Wu, C. L., Kandarian, S. C. \& Jackman, R. W. Identification of genes that elicit disuse muscle atrophy via the transcription factors p50 and $\mathrm{Bcl}-3$. PLoS One 6, e16171, doi:10.1371/journal.pone.0016171 (2011).

82 Tajrishi, M. M. et al. The TWEAK-Fn14 dyad is involved in age-associated pathological changes in skeletal muscle. Biochemical and biophysical research communications 446, 1219-1224, doi:10.1016/j.bbrc.2014.03.084 (2014).

83 Hindi, S. M. et al. Regulatory circuitry of TWEAK-Fn14 system and PGC1alpha in skeletal muscle atrophy program. FASEB J, (in press) (2014).

84 Kerr, J. F., Wyllie, A. H. \& Currie, A. R. Apoptosis: a basic biological phenomenon with wide-ranging implications in tissue kinetics. British journal of cancer 26, 239-257 (1972).

85 Schultz, D. R. \& Harrington, W. J., Jr. Apoptosis: programmed cell death at a molecular level. Seminars in arthritis and rheumatism 32, 345-369, doi:10.1053/sarh.2003.50005 (2003).

86 Zimmermann, K. C., Bonzon, C. \& Green, D. R. The machinery of programmed cell death. Pharmacology \& therapeutics 92, 57-70 (2001).

87 Elmore, S. Apoptosis: a review of programmed cell death. Toxicologic pathology 35, 495-516, doi:10.1080/01926230701320337 (2007).

88 Saelens, X. et al. Toxic proteins released from mitochondria in cell death. Oncogene 23, 2861-2874, doi:10.1038/sj.onc.1207523 (2004).

89 van Loo, G. et al. The serine protease Omi/HtrA2 is released from mitochondria during apoptosis. Omi interacts with caspase-inhibitor XIAP and induces enhanced caspase activity. Cell death and differentiation $\mathbf{9}$, 20-26, doi:10.1038/sj.cdd.4400970 (2002). 
90 Schimmer, A. D. Inhibitor of Apoptosis Proteins: Translating Basic Knowledge into Clinical Practice. Cancer Research 64, 7183-7190 (2004).

91 Zha, J., Harada, H., Yang, E., Jockel, J. \& Korsmeyer, S. J. Serine phosphorylation of death agonist BAD in response to survival factor results in binding to 14-3-3 not BCL-X(L). Cel/ 87, 619-628 (1996).

92 Chinnaiyan, A. M. et al. FADD/MORT1 is a common mediator of CD95 (Fas/APO-1) and tumor necrosis factor receptor-induced apoptosis. The Journal of biological chemistry 271, 4961-4965 (1996).

93 Muzio, M. et al. FLICE, a novel FADD-homologous ICE/CED-3-like protease, is recruited to the CD95 (Fas/APO-1) death--inducing signaling complex. Cell 85, 817-827 (1996).

94 Enari, M. et al. A caspase-activated DNase that degrades DNA during apoptosis, and its inhibitor ICAD. Nature 391, 43-50, doi:10.1038/34112 (1998).

95 Sakahira, H., Enari, M. \& Nagata, S. Cleavage of CAD inhibitor in CAD activation and DNA degradation during apoptosis. Nature 391, 96-99, doi:10.1038/34214 (1998).

96 Alway, S. E. \& Siu, P. M. Nuclear apoptosis contributes to sarcopenia. Exerc Sport Sci Rev 36, 51-57, doi:10.1097/JES.0b013e318168e9dc (2008).

97 Bargiela, A. et al. Increased autophagy and apoptosis contribute to muscle atrophy in a myotonic dystrophy type 1 Drosophila model. Dis Model Mech 8, 679-690, doi:10.1242/dmm.018127 (2015).

98 Dirks, A. \& Leeuwenburgh, C. Apoptosis in skeletal muscle with aging. Am J Physiol Regul Integr Comp Physiol 282, R519-527, doi:10.1152/ajpregu.00458.2001 (2002).

99 Libera, L. D. \& Vescovo, G. Muscle wastage in chronic heart failure, between apoptosis, catabolism and altered anabolism: a chimaeric view of inflammation? Curr Opin Clin Nutr Metab Care 7, 435-441, doi:00075197200407000-00013 [pii] (2004).

100 Silva, K. A. et al. Inhibition of Stat3 activation suppresses caspase-3 and the ubiquitin-proteasome system, leading to preservation of muscle mass in cancer cachexia. J Biol Chem 290, 11177-11187, doi:10.1074/jbc.M115.641514 (2015).

101 Talbert, E. E., Smuder, A. J., Min, K., Kwon, O. S. \& Powers, S. K. Calpain and caspase-3 play required roles in immobilization-induced limb muscle 
atrophy. J Appl Physiol (1985) 114, 1482-1489, doi:10.1152/japplphysiol.00925.2012 (2013).

102 Zhu, S. et al. Lack of caspase-3 attenuates immobilization-induced muscle atrophy and loss of tension generation along with mitigation of apoptosis and inflammation. Muscle Nerve 47, 711-721, doi:10.1002/mus.23642 (2013).

103 Nakayama, M. et al. Fibroblast Growth Factor-Inducible 14 Mediates Multiple Pathways of TWEAK-Induced Cell Death. The Journal of Immunology 170, 341-348, doi:10.4049/jimmunol.170.1.341 (2003).

104 Oeckinghaus, A., Hayden, M. S. \& Ghosh, S. Crosstalk in NF-[kappa]B signaling pathways. Nat Immunol 12, 695-708 (2011).

105 Meylan, E. \& Tschopp, J. The RIP kinases: crucial integrators of cellular stress. Trends in biochemical sciences 30, 151-159, doi:10.1016/j.tibs.2005.01.003 (2005).

106 Micheau, O. \& Tschopp, J. Induction of TNF receptor I-mediated apoptosis via two sequential signaling complexes. Cell 114, 181-190 (2003).

107 Kreuz, S., Siegmund, D., Scheurich, P. \& Wajant, H. NF-kappaB inducers upregulate cFLIP, a cycloheximide-sensitive inhibitor of death receptor signaling. Molecular and cellular biology 21, 3964-3973, doi:10.1128/mcb.21.12.3964-3973.2001 (2001).

108 Micheau, O., Lens, S., Gaide, O., Alevizopoulos, K. \& Tschopp, J. NFkappaB signals induce the expression of c-FLIP. Molecular and cellular biology 21, 5299-5305, doi:10.1128/mcb.21.16.5299-5305.2001 (2001).

109 Holler, N. et al. Fas triggers an alternative, caspase-8-independent cell death pathway using the kinase RIP as effector molecule. Nat Immunol 1, 489-495, doi:10.1038/82732 (2000).

110 Cho, Y. S. et al. Phosphorylation-driven assembly of the RIP1-RIP3 complex regulates programmed necrosis and virus-induced inflammation. Cell 137, 1112-1123, doi:10.1016/j.cell.2009.05.037 (2009).

111 Zhang, J., Yang, Y., He, W. \& Sun, L. Necrosome core machinery: MLKL. Cellular and molecular life sciences : CMLS 73, 2153-2163, doi:10.1007/s00018-016-2190-5 (2016).

112 Betteridge, D. J. What is oxidative stress? Metabolism - Clinical and Experimental 49, 3-8, doi:10.1016/S0026-0495(00)80077-3 (2000).

113 Kozakowska, M., Pietraszek-Gremplewicz, K., Jozkowicz, A. \& Dulak, J. The role of oxidative stress in skeletal muscle injury and regeneration: 
focus on antioxidant enzymes. Journal of muscle research and cell motility 36, 377-393, doi:10.1007/s10974-015-9438-9 (2015).

114 Halliwell, B. Free radicals and antioxidants: a personal view. Nutrition reviews 52, 253-265 (1994).

115 Halliwell, B. Free radicals and antioxidants: updating a personal view. Nutrition reviews 70, 257-265, doi:10.1111/j.1753-4887.2012.00476.x (2012).

116 Paul, T. Effect of a prolonged superoxide flux on transferrin and ferritin. Archives of biochemistry and biophysics 382, 253-261, doi:10.1006/abbi.2000.2027 (2000).

117 Zelko, I. N., Mariani, T. J. \& Folz, R. J. Superoxide dismutase multigene family: a comparison of the CuZn-SOD (SOD1), Mn-SOD (SOD2), and EC-SOD (SOD3) gene structures, evolution, and expression. Free radical biology \& medicine 33, 337-349 (2002).

118 Karnati, S., Luers, G., Pfreimer, S. \& Baumgart-Vogt, E. Mammalian SOD2 is exclusively located in mitochondria and not present in peroxisomes. Histochemistry and cell biology 140, 105-117, doi:10.1007/s00418-013-1099-4 (2013).

119 Ray, P. D., Huang, B.-W. \& Tsuji, Y. Reactive oxygen species (ROS) homeostasis and redox regulation in cellular signaling. Cellular Signalling 24, 981-990, doi:http://dx.doi.org/10.1016/i.cellsig.2012.01.008 (2012).

120 Davies, K. J., Quintanilha, A. T., Brooks, G. A. \& Packer, L. Free radicals and tissue damage produced by exercise. Biochemical and biophysical research communications 107, 1198-1205 (1982).

121 Powers, S. K. \& Jackson, M. J. Exercise-induced oxidative stress: cellular mechanisms and impact on muscle force production. Physiological reviews 88, 1243-1276, doi:10.1152/physrev.00031.2007 (2008).

122 Kondo, H., Miura, M. \& Itokawa, Y. Oxidative stress in skeletal muscle atrophied by immobilization. Acta physiologica Scandinavica 142, 527528, doi:10.1111/j.1748-1716.1991.tb09191.x (1991).

123 Powers, S. K., Kavazis, A. N. \& DeRuisseau, K. C. Mechanisms of disuse muscle atrophy: role of oxidative stress. American journal of physiology. Regulatory, integrative and comparative physiology 288, R337-344, doi:10.1152/ajpregu.00469.2004 (2005).

124 Espinosa, A., Henríquez-Olguín, C. \& Jaimovich, E. Reactive oxygen species and calcium signals in skeletal muscle: A crosstalk involved in 
both normal signaling and disease. Cell Calcium 60, 172-179, doi:http://dx.doi.org/10.1016/i.ceca.2016.02.010 (2016).

125 Pearson, T. et al. Skeletal Muscle Contractions Induce Acute Changes in Cytosolic Superoxide, but Slower Responses in Mitochondrial Superoxide and Cellular Hydrogen Peroxide. PloS one 9, e96378, doi:10.1371/journal.pone.0096378 (2014).

126 Sakellariou, G. K. et al. Studies of Mitochondrial and Nonmitochondrial Sources Implicate Nicotinamide Adenine Dinucleotide Phosphate Oxidase(s) in the Increased Skeletal Muscle Superoxide Generation That Occurs During Contractile Activity. Antioxidants \& Redox Signaling 18, 603-621, doi:10.1089/ars.2012.4623 (2012).

127 Powers, S. K., Ji, L. L., Kavazis, A. N. \& Jackson, M. J. in Comprehensive Physiology (John Wiley \& Sons, Inc., 2011).

128 Espinosa, A. et al. Myotube depolarization generates reactive oxygen species through $\mathrm{NAD}(\mathrm{P}) \mathrm{H}$ oxidase; ROS-elicited $\mathrm{Ca} 2+$ stimulates ERK, CREB, early genes. Journal of cellular physiology 209, 379-388, doi:10.1002/jcp.20745 (2006).

129 Kang, C., O'Moore, K. M., Dickman, J. R. \& Ji, L. L. Exercise activation of muscle peroxisome proliferator-activated receptor- $\gamma$ coactivator- $1 \alpha$ signaling is redox sensitive. Free Radical Biology and Medicine 47, 13941400, doi:http://dx.doi.org/10.1016/j.freeradbiomed.2009.08.007 (2009).

130 Strobel, N. A. et al. Antioxidant supplementation reduces skeletal muscle mitochondrial biogenesis. Medicine and science in sports and exercise 43, 1017-1024, doi:10.1249/MSS.0b013e318203afa3 (2011).

131 Contreras-Ferrat, A. et al. Insulin elicits a ROS-activated and an IP3dependent $\mathrm{Ca} 2+$ release, which both impinge on GLUT4 translocation. Journal of cell science 127, 1911 (2014).

132 Reid, M. B. Reactive Oxygen Species as Agents of Fatigue. Medicine and science in sports and exercise, doi:10.1249/mss.0000000000001006 (2016).

133 Moulin, M. \& Ferreiro, A. Muscle redox disturbances and oxidative stress as pathomechanisms and therapeutic targets in early-onset myopathies. Seminars in cell \& developmental biology, doi:http://dx.doi.org/10.1016/..semcdb.2016.08.003 (2016).

134 Shen, H. M. \& Pervaiz, S. TNF receptor superfamily-induced cell death: redox-dependent execution. FASEB journal : official publication of the Federation of American Societies for Experimental Biology 20, 1589-1598, doi:10.1096/fj.05-5603rev (2006). 
135 Madrigal-Matute, J. et al. TWEAK/Fn14 interaction promotes oxidative stress through NADPH oxidase activation in macrophages. Cardiovascular research 108, 139-147, doi:10.1093/cvr/cvv204 (2015).

136 Panguluri, S. K. et al. Genomic profiling of messenger RNAs and microRNAs reveals potential mechanisms of TWEAK-induced skeletal muscle wasting in mice. PloS one 5, e8760, doi:10.1371/journal.pone.0008760 (2010).

137 Maecker, $\mathrm{H}$. et al. TWEAK attenuates the transition from innate to adaptive immunity. Cell 123, 931-944, doi:10.1016/j.cell.2005.09.022 (2005).

$138 \mathrm{Li}, \mathrm{H}$. et al. Tumor necrosis factor-related weak inducer of apoptosis augments matrix metalloproteinase 9 (MMP-9) production in skeletal muscle through the activation of nuclear factor-kappaB-inducing kinase and p38 mitogen-activated protein kinase: a potential role of MMP-9 in myopathy. The Journal of biological chemistry 284, 4439-4450, doi:10.1074/jbc.M805546200 (2009).

139 Kumar, A., Bhatnagar, S. \& Paul, P. K. TWEAK and TRAF6 regulate skeletal muscle atrophy. Current opinion in clinical nutrition and metabolic care 15, 233-239, doi:10.1097/MCO.0b013e328351c3fc (2012).

140 Sato, S., Ogura, Y. \& Kumar, A. TWEAK/Fn14 Signaling Axis Mediates Skeletal Muscle Atrophy and Metabolic Dysfunction. Frontiers in immunology 5, 18, doi:10.3389/fimmu.2014.00018 (2014).

141 Dorn, G. W. Molecular Mechanisms That Differentiate Apoptosis from Programmed Necrosis. Toxicologic pathology 41, 227-234, doi:10.1177/0192623312466961 (2013).

142 Tsuchiya, Y., Nakabayashi, O. \& Nakano, H. FLIP the Switch: Regulation of Apoptosis and Necroptosis by cFLIP. International journal of molecular sciences 16, 30321-30341, doi:10.3390/ijms161226232 (2015).

143 Mandal, D., Mazumder, A., Das, P., Kundu, M. \& Basu, J. Fas-, caspase 8-, and caspase 3-dependent signaling regulates the activity of the aminophospholipid translocase and phosphatidylserine externalization in human erythrocytes. The Journal of biological chemistry 280, 3946039467, doi:10.1074/jbc.M506928200 (2005).

144 Liu, J., Wu, Y., Wang, B., Yuan, X. \& Fang, B. High levels of glucose induced the caspase-3/PARP signaling pathway, leading to apoptosis in human periodontal ligament fibroblasts. Cell biochemistry and biophysics 66, 229-237, doi:10.1007/s12013-012-9470-y (2013). 
145 Decker, P. \& Muller, S. Modulating poly (ADP-ribose) polymerase activity: potential for the prevention and therapy of pathogenic situations involving DNA damage and oxidative stress. Current pharmaceutical biotechnology 3, 275-283 (2002).

146 Hanson, B. Necroptosis: A New Way of Dying? Cancer Biology \& Therapy, 00-00, doi:10.1080/15384047.2016.1210732 (2016).

147 Vandenabeele, P., Declercq, W., Van Herreweghe, F. \& Vanden Berghe, $\mathrm{T}$. The role of the kinases RIP1 and RIP3 in TNF-induced necrosis. Science signaling 3, re4, doi:10.1126/scisignal.3115re4 (2010).

148 Vandenabeele, P., Grootjans, S., Callewaert, N. \& Takahashi, N. Necrostatin-1 blocks both RIPK1 and IDO: consequences for the study of cell death in experimental disease models. Cell death and differentiation 20, 185-187 (2013).

149 Langen, R. C. et al. Tumor necrosis factor-alpha inhibits myogenesis through redox-dependent and -independent pathways. American journal of physiology. Cell physiology 283, C714-721, doi:10.1152/ajpcell.00418.2001 (2002).

150 Bhatnagar, S. et al. Tumor necrosis factor-alpha regulates distinct molecular pathways and gene networks in cultured skeletal muscle cells. PloS one 5, e13262, doi:10.1371/journal.pone.0013262 (2010).

151 Bonnard, C. et al. Mitochondrial dysfunction results from oxidative stress in the skeletal muscle of diet-induced insulin-resistant mice. J Clin Invest 118, 789-800, doi:10.1172/JCl32601 (2008).

152 Terrill, J. R., Radley-Crabb, H. G., Grounds, M. D. \& Arthur, P. G. NAcetylcysteine treatment of dystrophic mdx mice results in protein thiol modifications and inhibition of exercise induced myofibre necrosis. Neuromuscul Disord 22, 427-434, doi:10.1016/j.nmd.2011.11.007 (2012).

153 Reid, M. B. \& Moylan, J. S. Beyond atrophy: redox mechanisms of muscle dysfunction in chronic inflammatory disease. J Physio/ 589, 2171-2179, doi:10.1113/jphysiol.2010.203356 (2011).

154 Hindi, S. M. et al. Regulatory circuitry of TWEAK-Fn14 system and PGC1alpha in skeletal muscle atrophy program. FASEB journal : official publication of the Federation of American Societies for Experimental Biology 28, 1398-1411, doi:10.1096/fj.13-242123 (2014). 


\section{CURRICULUM VITAE \\ Joseph D. McMillan IV \\ 1076 Everett Ave. \\ Louisville, KY 40204 \\ 502-741-9695 \\ jdmcmi02@gmail.com}

\section{Education}

M.S - Anatomical Sciences and Neurobiology

University of Louisville, Louisville, $\mathrm{KY}$

In progress, expected August 2016

GPA: $3.84 / 4.00$

GRE - Verbal 156; Quantitative - 154; Analytical Writing - 4.5

B.S. - Biology with a Cellular/Physiology focus

University of Louisville, Louisville, KY

May 2014

GPA: $2.88 / 4$

\section{Awards}

Dean's List

- Fall 2012, Spring 2013, Spring 2014

\section{Research Experience}

University of Louisville

Graduate Researcher, Principal Advisor: Ashok Kumar, PhD

- TWEAK cytokine in muscle development, injury, atrophy, and regeneration

\section{University of Louisville}

Undergraduate Summer Researcher, Principal Advisor: Paul Himes, PhD

- Signaling and gene regulation in pathogenic bacteria

\section{Publications}

TWEAK induces oxidative stress and causes mortality in cultured mouse primary myotubes. (2016) Joseph McMillan, Yuji Ogura, Guang Xiong, Ashok Kumar. In preparation. 


\section{Leadership}

Resident Assistant, ULH, Inc

August 2010 - July 2016

- Sole RA responsible for maintaining the infrastructure of the building, enforcing housing policies, and creating a safe, relaxed community

- Conducted passive programming via monthly bulletin boards, conducted monthly programs targeting various needs for student development, weekly desk shifts, four weekend shifts rotating between on-call duty and desk duty, weekly staff meetings

- Trained in fair housing policies, leasing duties, crisis response, QPR for suicide prevention, advocate

\section{Extracurricular Activities}

Volunteer at Homeless Shelter

January 2016 - Present

- Cook and serve breakfast to the homeless once a week at Jefferson St. Baptist Community

Volunteer Science Fair Judge

March 2016

- Judged Bioinformatics category at DuPont Manual Regional Science and Engineering Fair

Society for Neuroscience

August 2014 - Present

Philosophy Club

August 2013 - May 2014

- Participant in discussions and meetings with philosophy faculty and students and attended brown bag discussion group

Safety and Security Committee

August 2011 - May 2013

- Discussed safety concerns with staff from UofL campus housing properties and ULPD

- Postulated solutions and conducted programming to increase campus awareness

\section{Work Experience}

Desk Assistant, ULH, Inc.

August 2011 - July 2016

- Worked additional paid desk hours on weekends

Busser, Mark's Feed Store

2007 - January 2011

- Responsible for maintaining the cleanliness of the restaurant, bussed tables, assisted with host duties, assisted with dishwasher duties, replenished ice, engaged patrons

\section{Research Skills}


- Cell Culture

- Myoblast Isolation

- Myofiber Isolation

- DNA Primer/Vector Design

- PCR Design

- Mouse Breeding, Genotyping, and Maintenance of Colonies

- Mouse Sciatic Nerve Denervation

- Mouse Tissue Collection

- Mouse Tissue Sectioning

- Immunohistochemistry

- Western Blot

- QRT-PCR

- Biochemical Assays

- Microscopy and Imaging

- Data and Statistical Analysis

- Experimental Design 